\title{
CAN HETEROGENEITY OF POPULATIONS EXPLAIN DIFFERENCES IN MORTALITY?
}

James W. Vaupel,* Roland Rau, Carlo Giovanni Camarda and Kristin G. von Kistowski

CRR WP 2006-10

Released: March 2006

Draft Submitted: February 2006

Center for Retirement Research at Boston College

550 Fulton Hall

140 Commonwealth Ave.

Chestnut Hill, MA 02467

Tel: 617-552-1762 Fax: 617-552-1750

http://www.bc.edu/crr

* James W. Vaupel is the Founding Director of the Max Planck Institute for Demographic Research and the Principal Investigator of this paper. The research reported herein was performed, in part, pursuant to a grant from the U.S. Social Security Administration (SSA) funded as part of the Retirement Research Consortium. The findings and conclusions expressed are solely those of the authors and do not represent the views of SSA, any agency of the Federal Government, the Max Planck Institute for Demographic Research or Boston College.

(c) 2006, by James W. Vaupel, Roland Rau, Carlo Giovanni Camarda and Kristin G. von Kistowski. All rights reserved. Short sections of text, not to exceed two paragraphs, may be quoted without explicit permission provided that full credit, including ( $)$ notice, is given to the source. 


\section{About the Center for Retirement Research}

The Center for Retirement Research at Boston College, part of a consortium that includes a parallel centers at the University of Michigan and the National Bureau of Economic Research, was established in 1998 through a grant from the Social Security Administration. The goals of the Center are to promote research on retirement issues, to transmit new findings to the policy community and the public, to help train new scholars, and to broaden access to valuable data sources. Through these initiatives, the Center hopes to forge a strong link between the academic and policy communities around an issue of critical importance to the nation's future.

\section{Center for Retirement Research at Boston College \\ 550 Fulton Hall \\ 140 Commonwealth Ave. \\ Chestnut Hill, MA 02467 \\ phone: 617-552-1762 fax: 617-552-0191 \\ e-mail: crr@bc.edu \\ http://www.bc.edu/crr}

\section{Affiliated Institutions:}

American Enterprise Institute

The Brookings Institution

Center for Strategic and International Studies

Massachusetts Institute of Technology

Syracuse University

Urban Institute 


\section{Abstract}

We investigate whether heterogeneity can explain the differences in mortality between the United States and a more homogeneous country, i.e. Japan. The background of the analysis is the growing gap between life-expectancy in the United States and the world record leader since the 1980s. This development is mirrored in the decelerated improvements made against mortality during the last 25 years - especially for women.

Our hypothesis is that it is possible to have survival improvements at a steady pace across all population subgroups. The proportion of the population subgroups which perform relatively well decreased over time whereas poor performing subgroups became more important. The consequence of this compositional change since the 1980s would be the observed levelling off in survival improvements on the population level.

Since official mortality estimates in the US are of poor quality, we estimate mortality rates via the extinct cohort method using Medicare enrollment data from the Social Security Administration due to their higher quality.

If our hypothesis was true, we should see little differences in the development of mortality rates between the best performing subgroups in the United States and Japan. We compared mortality rates between Japanese women and white women in the US from states who (a) either had the highest life expectancy or (b) the highest median household income or (c) the largest gross state product per head. Regardless of the choice of indicator, mortality rates levelled-off in the United States for those best performance subgroups as for the whole population.

The preliminary conclusion is therefore that compositional changes (heterogeneity) in the US population can not explain the widening gap between US life expectancy and best practice life expectancy. 


\section{Introduction}

\section{General Survival Improvements}

From the beginning of the twentieth century until today mankind has been extremely successful in lowering mortality rates to previously unprecedented levels. This is reflected in the increase in record life expectancy which is a good approximation for what is possible at a given point in time ("technological frontier"). Since 1840, record life expectancy has risen almost linearly by a rate of roughly three months for every calendar year passed (Oeppen and Vaupel, 2002): in 1900 women in New Zealand had the highest life expectancy at birth with 59.95 years. One hundred years later, the female population of Japan is the record-holder with 84.62 years (Oeppen and Vaupel, 2002). This development is depicted in Figure 1.1, the deviations from the linear trend are relatively minor. ${ }^{1}$ This trend has also persisted during the last five years. The most recent data for the year 2004 show for Japan a value of 85.59 years.

Looking at the increase in life expectancy since 1840, for the first 100 years this development was mainly caused by successfully combating the risks during early life. Most notably, infant mortality was lowered to historically unpredecented levels. Since the 1950s and even more pronounced since the 1970s — the increase in life expectancy can be traced back to survival improvements for older ages, in particular for the oldest-old (ages 80+). This has been shown, for example, by Vдіпц Kannisto and James W. Vaupel until the 1990s (e.g. Kannisto, 1994, 1996; Kannisto et al., 1994; Vaupel, 1997). Using the most recent data from the KannistoThatcher-Database, ${ }^{2}$ one can show that this trend has continued until nowadays.

Figure 1.2 illustrates the development of the probability of dying, denoted by $q(x)$ (calculated as shown in Preston et al., 2001), for the ages 80, 85, and 90 for the time-period from 1950 until 2001 for France, Sweden, and Japan which represent the countries with lowest mortality worldwide. Due to relatively small numbers, the curves are fluctuating for the first years at the oldest plotted age (90). Nevertheless, the trend is obvious: in all three countries mortality is constantly decreasing for women as well as for men at the highest ages. Especially for women in Japan, the slope of decreases in mortality (and complementarily the increases in survival) is remarkable (see also Table 1.1): within approximately 50 years, the mortality rates

\footnotetext{
${ }^{1}$ James C. Riley called this development "the crowning achievement of the modern era" (Riley,
} 2001, p. 1). 
for ages 80 and 85 are only one third of the levels from 1950. For age 90, the level of mortality roughly halved. Table 1.1 also shows that mortality improved on average by more than 2.5 percent for age 80 in Japan during that period. ${ }^{3}$

\section{The Situation in the United States}

The United States has never been the world record holder in life expectancy. Figure 1.3 compares the development of life expectancy between the United States (light-blue) and other countries including best-practice life expectancy.

The first reliable data for the US are available from the year 1901 (Human Life-Table Database, 2005). By that time, life expectancy of women in the United States was 50.86 years and was hence lagging roughly 10 years behind the world record leader New Zealand (60.55, see supplementary material of Oeppen and Vaupel (2002)). The United States was catching up to the world record leader until the 1950s. The difference between the US and the best practice in terms of female life expectancy at birth was reduced to two years in 1950 (United States: 71.13 years, Best-Practice (Norway) 73.21 years). Until approximately 1980, life expectancy in the United States remained relatively close to the record-holding countries (Iceland, the Netherlands, Norway, Sweden). Since the 1980s, however, the gains in life expectancy have slowed down in the United States in comparison to the record holder (Iceland until 1984, Switzerland in 1985, Japan since 1986). In the year 2000, female life expectancy was 79.7 years in the United States (U.S. Census Bureau, 2004). Japanese women's life expectancy was about five years higher (84.62 years). Or put into other terms: the life expectancy of women in the United States in the year 2000 was lagging behind the record set by the best performing country approximately 20 calendar years before (Iceland, 1979: 79.73 years, see supplementary material of Oeppen and Vaupel (2002)).

This effect in levelling off is mirrored in the development of mortality rates at advanced ages. Figure 1.4 shows the probability of dying $(q(x))$ for ages 80,85 , and 90 for the United States, France, Sweden, and Japan for the years 1950 until 2001. ${ }^{4}$ One can recognize that the

\footnotetext{
${ }^{2}$ Available online at: http://www.demogr.mpg.de/databases/ktdb/

${ }^{3}$ Average annual improvement has been calculated as percent per year compounded continuously as shown in Keyfitz and Caswell (2005) which gives approximately the same results as the method shown in the appendix of Kannisto et al. (1994).

${ }^{4}$ For the United States, reliable data were only available for the years 1959-2000.
} 
United States enjoyed the lowest mortality for women and men alike at the highest ages until about $1980 .{ }^{5}$ Since then, mortality rates fell less rapidly in the United States than in the three other countries which coincides with being overtaken by Japan and France.

Figure 1.5 makes this development even more visible. The average annual improvement in female mortality in successive decades has been plotted for Japan and the United States for three age-groups (80-84 years, 85-89 years, 90-94 years). The first element of the solid red line depicts the average annual improvement in mortality in Japan for ages 80 to 84 by comparing the decade 1970-79 with 1960-69. The value of approximately 2.2 denotes that mortality rates dropped by 2.2 percent each year during these two decades. One can recognize by the green and blue dotted lines that survival improvements were stronger in the United States for the age groups 85-89 years and 90-94 years than in Japan for the first few years of comparison. During the observation period the pace in mortality improvements developed antagonistically in both countries: while Japan's speed in lowering mortality increased over time, the speed in the United States slowed down and is close to a standstill when comparing the 1990s with the 1980s.

\section{Explanations}

To understand demographic phenomena, one can typically refer to three idealtypen (Weber, 1980) of explanation which are not mutually exclusive: Level-0, Level-1 and Level-2 explanations (Vaupel and Canudas Romo, 2001).

A Level-0 explanation is that there are problems with the data. Data quality is an apparent problem in the United States (e.g. Coale and Kisker, 1986) and will be addressed in Section 2 in this report.

A Level-1 explanation is the explanation one is typically interested in. It implies a change in the underlying variable (i.e. mortality in our case). Meslé and Vallin (2005), for example, investigated gains and losses in life expectancy by various causes of death. They showed "a growing concern with mental disorders." The gains which the United States made between 1984 and 2000 in circulatory diseases (cardiovascular diseases and cerebrovascular diseases) are counter-acted by mental disorders (incl. Alzheimers). The antagonistic effect of mental disorders is, however, not strong enough to completely explain the lag between the US on the one hand and

\footnotetext{
${ }^{5}$ If US mortality had been the lowest across all ages, the United States would have been the best performing country in the world in terms of life expectancy. The differential in the past (until
} 
Japan on the other hand: Meslé and Vallin estimated that the growing importance of mental disorders in the United States lowered life expectancy for women by 0.34 years. For France and Japan, these effects were almost non-existent (Meslé and Vallin, 2005, p. 9).

We investigate whether the divergent trend in the United States can be rather understood by a Level-2 explanation: a change in the composition of the population. At least since the publication of the monograph "Differential Mortality in the United States" by Kitagawa and Hauser (1973) it is well known that large mortality differences exist in the United States between various population subgroups. These subgroups can be defined by sex, ethnicity, income, education, marital status (see as examples for the large amount of literature on this subject: Kunst, 1997; Rogers et al., 1995). A recent study shows that these mortality differences persist also at very high ages (Hoffmann, 2005).

We therefore put forward the hypothesis that the levelling-off in the United States is the effect of a compositional effect: steady progress could be actually possible in all population subgroups. Over time, population subgroups with unfavorable characteristics gained weight in the US population while relatively well-performing subgroups contribute less to the population nowadays than they used to do. It would result in the observed levelling-off in gains in life expectancy suggesting a change in mortality trends albeit it is only a change in the composition of the population. This is one of the "ruses" heterogeneity can play and has been known to and understood by demographers for at least twenty years (Vaupel and Yashin, 1985).

More specifically, we asked: How did mortality develop in the best-performing population subgroups in the United States compared to Japan? If our hypothesis of a compositional effect was true, we should see remarkable improvements in the best-performing population subgroups. We decided to contrast these best-practice results from the United States with Japan since this is a fairly homogeneous country with the lowest mortality at advanced ages.

\section{Consequences for Public Policy}

Understanding past mortality change is essential to predict future mortality developments. Will the progress made in survival remain as slow as it did during the last twenty years or will the United States catch up with the trend of the leading countries in the world? In August 2005, the Social Security Administration published life table estimates for the United States for the years

1980) must, thus, largely be attributed to differences at younger ages. 
1900-2100 (Bell and Miller, 2005). Life expectancy for women is assumed to reach 86.40 years by 2100 . According to this official estimate, the current level of life expectancy in Japan of 85.59 years would be exceeded in the United States only in 2086 implying a lag of roughly 80 calendar years in the United States. It has been suggested that the underlying decrease in mortality levels is too low (Wilmoth, 2005). ${ }^{6}$ Too pessimistic official estimates in terms of progress made against mortality would have major implications for the Social Security System. Since it is mainly based on a "pay-as-you-go"-scheme, more people would be beneficiaries in the future than currently predicted. The impact on taxation has been discussed, for example, in Lee and Tuljapurkar (1997) and Lee (2000). Lee and Tuljapurkar (1997, p. 79) conclude:

"According to our simulation using the SSA mortality and fertility assumptions, the balanced budget tax rate would have to rise from $12 \%$ now to $20 \%$ in 2070 . Based on the Lee-Carter point forecast, the tax rate instead would have to rise to $24 \%$. Some forecasters, however, foresee mortality declines that are dramatically larger than these, viewing a life expectancy of $90-100$ or more as a real possibility [...]. If life expectancy rose to 90 or 100 years by 2070 , the balanced tax rate would have to rise to $27 \%$ or $32 \%$ of taxable payroll."

Please note that their simulations were based on earlier, even more conservative, forecasts. ${ }^{7}$ The most positive scenario of an increase in the tax rate from $12 \%$ to $20 \%$ becomes therefore more and more unlikely.

\section{Data \& Methods}

\section{Data Problems in the United States}

Official mortality estimations in the United States at advanced ages typically have relatively low quality - especially for higher ages. Kannisto (1994), for example, judges that data from the United States compared to other Western industrialized countries are of "weak quality."

\footnotetext{
${ }^{6}$ See also Vaupel and Schnabel (2004) for an approach to forecast national life expectancy based on forecasting best-practice life expectancy.

${ }^{7}$ They used data where the sexes-combined life-expectancy was 80.7 years in 2070 . The latest update from August 2005 assumes a higher life expectancy in the year 2070 since this value is by then almost exceeded by male life expectancy ( 80.97 years).
} 
A similar assessment has been made by Coale and Kisker (1986, p. 2): "At the highest ages data for the United States appear to be unusually weak for a more developed country." Also Bert Kestenbaum (1992, p. 565) from the Office of the Actuary of the Social Security Administration bemoans "...the unreliability of the underlying data. Irrefutable evidence of the shortcomings of data sets for the extreme aged comes from their implausible products, such as decreases in mortality rates with age and substantial numbers of persons living at ages past 110 ...." These problems can be explained by a variety of reasons such as changing methodology for estimates and a changing data-base for the estimates (Coale and Kisker, 1986) ${ }^{8}$ as well as with problems of the US civil registration system (Meslé and Vallin, 2005).

A "famous" outcome of the low data quality is the so-called "mortality crossover": AfroAmericans showed lower mortality than whites at advanced ages whereas they suffer from higher mortality at younger ages. Using Medicare Data to correct official estimates, it has been demonstrated that the mortality of Afro-Americans was also higher at advanced ages (Preston et al., 1996).

Our own checks for the quality of official estimates of mortality in the United States revealed some implausability which is depicted in Figure 2.1: for each state a separate line has been plotted for the logarithm of the probability of dying. The variability on mortality age 65 could be expected and also a slight convergence can be plausible. After age 95, however, mortality is exactly ${ }^{9}$ the same in each of the 50 States of the United States. This is impossible.

The major conclusion from the findings of the literature and from our own investigations was that official estimates for the United States are not as accurate as is required for a proper analysis of mortality. The literature pointed, however, at another dataset: the Medicare records of the Social Security Administration. These data have been used for the construction of U.S. life tables for the years 1969-71 and are still used nowadays: "For the oldest age groups, [...], the rates were corrected using data from the Social Security Administration” (Day, 1996, p. 28). They were also used in research — not only by Preston et al. (1996) — but also by Kestenbaum (1992), Parnell and Owens (1999) and Lauderdale and Kestenbaum (2002), for instance.

\footnotetext{
${ }^{8}$ Coale and Kisker (1986) note that US Life Tables have been constructed by extrapolating the highest ages via "various mathematical formulae." Furthermore, estimates were sometimes based on mortality records of surviving Civil War Veterans (1950 and 1960); in the years 1969-1971, Medicare records were used for some ages.

${ }^{9}$ The mortality levels are the same for the given level of precision of four digits.
} 


\section{Data Description}

The data of our analysis were a subset of the Social Security Administration's Master Beneficiary Record (MBR). Following the suggestions of the literature for data quality (Kestenbaum, 1992; Lauderdale and Kestenbaum, 2002; Parnell and Owens, 1999), only people who were Medicare Part B insured were included. As Lauderdale and Kestenbaum (2002, p. 531) explain:

"We targeted the population enrolled in Medicare Part B rather than the population entitled to social security benefits, in part, because Medicare coverage is more complete than social security coverage at the oldest ages. Overall about $95 \%$ of persons 65 and older are enrolled in Part B, with many of those not enrolled being the younger elderly still participating in employee insurance plans. Although coverage could be enhanced by also including persons who only enrolled in Medicare Part A (hospital insurance), many persons appear to have only Part A coverage have, in fact, died or emigrated."

Since Medicare started in 1966, one would expect that the range of data-analysis should cover the years 1966 until the late 1990s for the age-range 65 to 100+. Some preliminary mortality analysis showed us, however, that mortality estimates before 1976 and after 1994 were completely out of range. Please see Figure A1 in the Appendix. Since the data only contained birth cohorts before 1916, we were restricted to analyzing the data for 1976 until 1994 for an agerange starting at 65 years. Table 2.1 shows that despite those limitations there were still almost 20 million records available. To disentangle various population-subgroups we were able to break down the data by sex (women, men), state of residence ( 50 states) and by ethnicity (white, otherthan-white). It might have been desirable to have further covariates available such as education or income. They were, however, not included in these data. Nevertheless we can consider state of residence as an ecological proxy variable for income inequality — similar to the study published in the British Medical Journal on "Education, income inequality, and mortality: a multiple regression analysis" (Muller, 2002).

\section{Quality of the Social Security Data}

Being aware of the problems of the quality of data in the United States, we scrutinized the Social Security Data thoroughly for implausability and quality. We compared our results also with other data we considered to be trustworthy. See for example the comparison by sex for our 
data indicated by "SSA" in red vs. the estimates from the Human Mortality Database (http://www.mortality.org) in blue (HMD) in Figures A2-A4 in the Appendix. We concluded that the Social Security Data are of sufficient quality.

\section{Methods}

Although the data from the Social Security Administration are considered to have higher quality than official estimates, we endeavored to ensure the highest quality in our mortality estimates. To estimate mortality rates and/or the probability of dying one needs to know the number of people who died in a certain interval as well as the number of people exposed to the risk of dying in the same interval. Population estimates at advanced ages are typically less reliable than information about deaths. While the standard problems, such as age-heaping (see, for example, Alho and Spencer, 2004), are unlikely for our longitudinal, individual-level data, we can not exclude the possibility that some records are still kept erroneously. We decided therefore to rely only on death counts which require an additional proof (i.e. a death certificate). The socalled "Extinct-Cohort-Method" allows us to estimate the exposed population using only information about death. This approach has been pioneered by Vincent (1951) and Depoid (1973) and is the standard tool nowadays to estimate populations for mortality databases such as the Kannisto-Thatcher Database and the Human Mortality Database.

For our analysis, we used an "Exact-Age / Exact-Birth-Year" approach (see Figure A5 as well as the section on methodology in the Appendix). We considered that a cohort is extinct at age 110 which appears to be a reasonable cut-off age to estimate mortality up to age 100 (the population at risk at age 99 is, hence, the number of deaths at ages $99,100,101, \ldots, 110$ for a specific one-year birth cohort).

\section{Results}

\section{Choice of Indicators}

In the first step of our analysis we compare Japan with the best performing population subgroups in the United States. If heterogeneity and the changing composition of the population play a major role, one should expect that the best-performing population subgroup does not show 
the same levelling-off as has been observed for the whole US population. We measure performance of subgroups by three indicators:

Life Expectancy: Using the U.S. Decennial Life Tables for 1989-91, which have been published for every state (e.g. National Center for Health Statistics, 1998), we picked those states with the five highest life expectancy values for white females.

Median Income per Household: The US Census Bureau publishes the Median Income for fourperson families by state for every year (U.S. Census Bureau, 2005). Median family income in a state is taken as a proxy variable as "the inverse relationship between income and mortality persists for women and men, the young and the old, majority and minority populations, and the married and the unmarried" (Rogers et al., 1995, p. 119). Again we picked the best five performing states and analyzed mortality for white women in relation to women in Japan. 1985 has been used as the year of reference because it is in the middle of our observation period (1976-94).

Gross State Product per Head: As an alternative to the median household income, we also used the Gross State Product per Head. At least since Preston (1976), the effect of the GDP on mortality and life-expectancy is known to demographers. The Gross State Product is published annually by the Bureau of Economic Analysis (Bureau of Economic Analysis, 2005). State population estimates have been obtained by interpolating the census results published by the US Bureau of the Census. Again we picked for the year 1985 the five best performing states and contrasted mortality of white women with Japanese female mortality.

The Top-5 performing states for each indicator are given in Table 3.1. Correlation analysis shows that Median Household Income and Gross State Product per Head point in the same direction (Kendall's $\tau$ : 0.568066, p-value: 4.086e-09) whereas the relationships between life expectancy on the one hand and either Median Household Income or Gross State Product per Head on the other hand did not yield significant results. 


\section{Indicator: Life-Expectancy Performance}

For each of the indicators, we are looking at the development of mortality over time for various ages and comparing it to Japan. For a first comparison, we plotted a mortality-surface for Japanese women for the age-range 80-100 for our observation window 1976-1994 (Figure 3.1). Similar to topographic maps, various colors depict various levels of mortality. Lowest mortality rates are plotted in blue colors. With increasing mortality, colors become green, yellow and brown. In Japan, mortality is decreasing over time across all observed ages as indicated by the positive gradient for all levels of mortality. Generally speaking, within the observation period, mortality levels were reached in 1994 four (age-) years later than in 1976. For instance, mortality at age 83 in the year 1976 is approximately equal to the mortality level at age 87 in year 1994 $\left(q(x)_{83 ; 1976}=0.103538 \quad ; q(x)_{87 ; 1994}=0.102688 \quad\right)$. Comparing the figure for Japan with

Figure 3.2 - which shows the probability of dying for women in the five best performing states of the US (Hawaii, Iowa, Minnesota, North Dakota, and South Dakota) for the same age-range and calendar-time - one can quickly identify that there is almost no progress being made in the United States. While in Japan mortality dropped at all ages, the Top-5 states in the US made almost no progress between 1976 and 1994. All contour lines on the mortality surface-map remained relatively flat.

The probabilities of dying for ages 80 and 85 have been plotted for Japan and "Top-5" in conjunction with data for women for the whole of the United States in Figure 3.3. ${ }^{10}$ The blue line for Japan shows a monotonous decline whereas the slope for all women in the United States (green) is less steep. Approximately in the year 1985, Japan displayed lower mortality rates than the United States. The red-line indicates mortality at age 80 for White females in the Top-5 states of life-expectancy. Their development over time shows the same pattern as the whole of the United States does - only at a lower level. Hence, Japanese mortality at age 80 was below the Top-5 mortality only in 1990. The development at age 85 is almost identical to the pattern observed at age 80: Japan is in stark contrast with the two curves plotted for the United States. Again we have a strong decrease in mortality rates on the one hand (Japan) while the improvements in survival on the other hand (US, Top-5-US) were much less pronounced.

\footnotetext{
${ }^{10}$ Estimates (indicated by ${ }^{\circ}$ ) have been slightly smoothed to make the existence of trends more visible using Tukey's Median Smoother (Tukey, 1977).
} 
This is already contradicting the hypothesis that a varying development over time for various population subgroups could explain the stagnating trend in life expectancy improvements in the United States. If heterogeneity plays a role in explaining the trend in the United States as outlined, for example, in Figure 1.3, the best performing subpopulations in the United States should still show a considerable downward gradient in mortality rates. One possibility is, however, that our indicator to choose the best-performance states on the basis of life expectancy estimates from 1990 was not a good idea. Therefore we investigate on the following pages whether the indicators median household income and GDP per head are better suited.

\section{Indicator: Median Household Income}

Figure 3.4 shows the surface map of mortality in the 5 states of the United States whose median household income was highest in 1985. Similar to Figure 3.2, the progress made over time across all ages is almost negligible as indicated by the almost horizontal "topographic" lines. Figure 3.5 illustrates how female mortality developed over time at ages 80 and 85 in Japan, the United States as a whole, and in the 5 states which had the highest median household income. The blue and the green lines are identical to Figure 3.3. The red line for the Top-5 household income performers is almost indistinguishable from the green line representing all women in the United States. One can recognize that the indicator "median household income" is not appropriate to differentiate the states showing highest life expectancy from the remaining US population.

\section{Indicator: Gross State Product}

Finally, we investigated the indicator GDP per head. Preston (1976) showed for a comparison for national population that there is a positive relationship between National Income Per Capita and life expectancy at birth. Hence, one should assume that also within a population, the subgroups with the highest gross state product per head should be leading in survival improvements. If one investigates, however, Figure 3.6, little progress has been made for the five states with the highest gross state product per head in 1985 (Alaska, Connecticut, Delaware, New York, Wyoming). Again, one observes that the development of mortality levels over time is relatively horizontal, indicating only little progress over time. Also Figure 3.7 emphasizes this 
result. Age-specific mortality rates for ages 80 and 85 over time were more or less identical for women in the whole of the US and women in the Top-5 performers.

\section{Conclusions}

Life expectancy at birth for women in the United States has been among the highest in the world. Since the 1980s, however, a deceleration of life expectancy improvements could be observed in the US, generating an increasing gap in relation to the world record holding country. The reasons for this development are not yet understood.

We asked whether compositional changes in the US population could have caused this levelling off. In this case mortality can decrease at a steady pace across all population subgroups which can be characterized by factors with a known mortality differential such as race, sex, religion, income, or educational background. The extent of the decrease, however, would differ across these groups. Over time, subgroups performing less favorably gained importance whereas the proportions of the subgroups performing very well became smaller. If this were the case, the increasing gap in life expectancy between the United States and the world record holder, which has been Japan since the mid-1980s, could be explained by diverging mortality rates in a heterogeneous society.

In order to test this hypothesis we chose to examine the development of mortality decline over time in US subpopulations performing very well and to compare these developments to the decrease in mortality in Japan. Taking into consideration the constraints linked to the data available, we selected the female and Caucasian subpopulations of the five US States performing best in terms of life expectancy, gross state product per head and median household income, respectively.

If compositional change were responsible for the deceleration in mortality decrease, these best performing subpopulations should show a rate of decrease similar to the well performing population of Japan. In contrast, other subpopulations performing badly should show a much slower decrease in mortality which eventually caused the lower life expectancy in the US. However, the subpopulations performing best in terms of life expectancy showed a much slower pace in survival improvements than our country of reference, Japan. Neither did the US American subpopulations performing best in GDP per head or median income - the two other indicators chosen - show survival improvements to the extent Japan does. 
These best-practice US American subpopulations show stagnating improvements in survival (just like we would expect of the subpopulations performing less well). Our conclusion is therefore that the deceleration of life expectancy improvements since the 1980s is most likely a general characteristic of the American population and not a characteristic confined to a number of subpopulations gaining importance. We do not find evidence that compositional change and major differences in survival improvements between various subpopulations cause the comparatively slow rise in life expectancy. Instead, the results indicate that survival improvements at higher ages are developing worse in the US than in many other developed countries - even if the best performing subpopulations are considered. Although old-age survival has increased in the United States since 1950, there is apparently still a larger potential for further increases in life expectancy than in many other industrialized countries. Heterogeneity of populations, however, cannot be the major cause for the fact that the gap between the US life expectancy trajectory and the linear climb in life expectancy is widening. 


\section{References}

Alho, J. M. and B. D. Spencer (2004). Statistical Demography and Forecasting. Springer Series in Statistics. New York, NY: Springer.

Bell, F. C. and M. L. Miller (2005). Life Tables for the United States Social Security Area 19002100. SSA Pub. No. 11-11536. Social Securtiy Administration, Office of the Chief Actuary.

Bureau of Economic Analysis (2005). Gross State Product. available online at: http://www.bea.doc.gov/bea/regional/gsp/.

Coale, A. J. and E. E. Kisker (1986, August). An Investigation of the Quality of Old-age Mortality Data. Report to the National Center for Health Statistics. August 8, 1986.

Day, J. C. (1996). Population Projections of the United States by Age, Sex, Race and Hispanic Origin: 1995 to 2050. U.S. Bureau of the Census, Current Population Reports, P25-1130. Washington, DC: U.S. Government Printing Office.

Depoid, F. (1973). La Mortalité des Grands Vieillards. Population 28, 755-792.

Hoffmann, R. (2005). Do socioeconomic mortality differences decrease with rising age? Demographic Research 13, 35-62.

Human Life-Table Database (2005, December). Data by country: United states. Contributions from Vдіпц Kannisto, accessible online at: http://www.lifetable.de.

Kannisto, V. (1994). Development of oldest-old mortality, 1950-1990: Evidence from 28 developed countries. Monographs on Population Aging, 1. Odense, DK: Odense University Press.

Kannisto, V. (1996). The Advancing Frontier of Survival. Monographs on Population Aging, 3. Odense, DK: Odense University Press.

Kannisto, V., J. Lauritsen, A. R. Thatcher, and J. W. Vaupel (1994). Reductions in mortality at advanced ages: Several decades of evidence from 27 countries. Population and Development Review 20, 793-810.

Kestenbaum, B. (1992). A Description of the Extreme Aged Population Based on Improved Medicare Enrollment Data. Demography 29, 565-580.

Keyfitz, N. and H. Caswell (2005). Applied Mathematical Demography. Third Edition. New York, NY: Springer.

Kitagawa, E. M. and P. M. Hauser (1973). Differential mortality in the United States: A Study in Socioeconomic Epidemiology. Cambridge, MA: Harvard University Press. 
Kunst, A. (1997). Cross-national comparisons of socio-economic differences in mortality. Ph. D. thesis, Department of Public Health, Erasmus University Rotterdam, Rotterdam, NL.

Lauderdale, D. S. and B. Kestenbaum (2002). Mortality Rates of Elderly Asian American Populations Based on Medicare and Social Security Data. Demography 39, 529-540.

Lee, R. (2000). Long Term Population Projections and the US Social Security System. Population and Development Review 26, 137-143.

Lee, R. and S. Tuljapurkar (1997). Death and Taxes: Longer Life, Consumption, and Social Security. Demography 34, 67-81.

Meslé, F. and J. Vallin (2005, March/April). Why do american trends in female old age mortality diverge from those of other advanced industrialized countries? Paper presented at the 2005 PAA Meeting.

Muller, A. (2002). Education, income inequality, and mortality: a multiple regression analysis. British Medical Journal 324, 1-4.

National Center for Health Statistics (1998). U.S. decennial life tables for 1989-91, vol II, State life tables no. 5, California. Hyattsville, MD: Centers for Disease Control and Prevention.

Oeppen, J. and J. W. Vaupel (2002). Broken Limits to Life Expectancy. Science 296, 1029-1031.

Parnell, A. M. and C. R. Owens (1999). Evaluation of U.S. Mortality Patterns at Old Ages Using the Medicare Enrollment Data Base. Demographic Research 1.

Preston, S. H. (1976). Mortality Patterns in National Populations. With special reference to recorded causes of death, Chapter 4: Contribution of Economic Factors to Declines in Mortality during the Twentieth Century, pp. 62-88. New York, NY: Academic Press.

Preston, S. H., I. T. Elo, I. Rosenwaike, and M. Hill (1996). African-American Mortality at Older Ages: Results of a Matching Study. Demography 33, 193-209.

Preston, S. H., P. Heuveline, and M. Guillot (2001). Demography. Measuring and Modeling Population Processes. Oxford, UK: Blackwell Publishers.

Riley, J. C. (2001). Rising Life Expectancy. A Global History. Cambridge, UK: Cambridge University Press.

Rogers, R. G., R. A. Hummer, and C. B. Nam (1995). Living and Dying in the USA. Behavioral, Health and Social Differentials of Adult Mortality. San Diege, CA: Academic Press.

Tukey, J. W. (1977). Exploratory Data Analysis. Reading, MA: Addison-Wesley.

U.S. Census Bureau (2004). Statistical Abstract of the United States 2004-2005 (124th ed.). Washington, DC: U.S. Department of Commerce. 
U.S. Census Bureau (2005). Median Income for 4-Person Families, by State. available online at: http://www.census.gov/hhes/income/4person.html.

Vaupel, J. W. (1997). The remarkable improvements in survival at older ages. Philosophical Transactions of the Royal Society of London: Biological Sciences 352, 1799-1804.

Vaupel, J. W. and V. Canudas Romo (2001, November 18). Analysis of Population Changes and Differences. Methods for Demographers, Statisticians, Biologists, Epidemiologists, and Reliability Engineers. Konrad Zuse Str. 1, D-18057 Rostock, Germany: Max Planck Institute for Demographic Research, Rostock, Germany.

Vaupel, J. W. and S. Schnabel (2004). Forecasting best-practice life expectancy to forecast national life expectancy. Paper presented at the 2004 PAA Meeting.

Vaupel, J. W. and A. I. Yashin (1985). Heterogeneity's ruses: Some surprising effects of selection on population dynamics. The American Statistician 39, 176-185.

Vincent, P. (1951). La Mortalité des Vieillards. Population 6, 181-202.

Weber, M. (1980). Wirtschaft und Gesellschaft: GrundriЯ der verstehenden Soziologie (originally published 1922) (5th, revised ed.). Tьbingen, D: Mohr.

Wilmoth, J. R. (2005, May). Overview and discussion of the social security projections. Working Paper for the 2003 Technical Panel on Assumptions and Methods, Social Security

Advisory Board, Washington D.C. 
Figures and Tables

Figure 1.1: Record Life Expectancy from 1840 to 2000 for Women

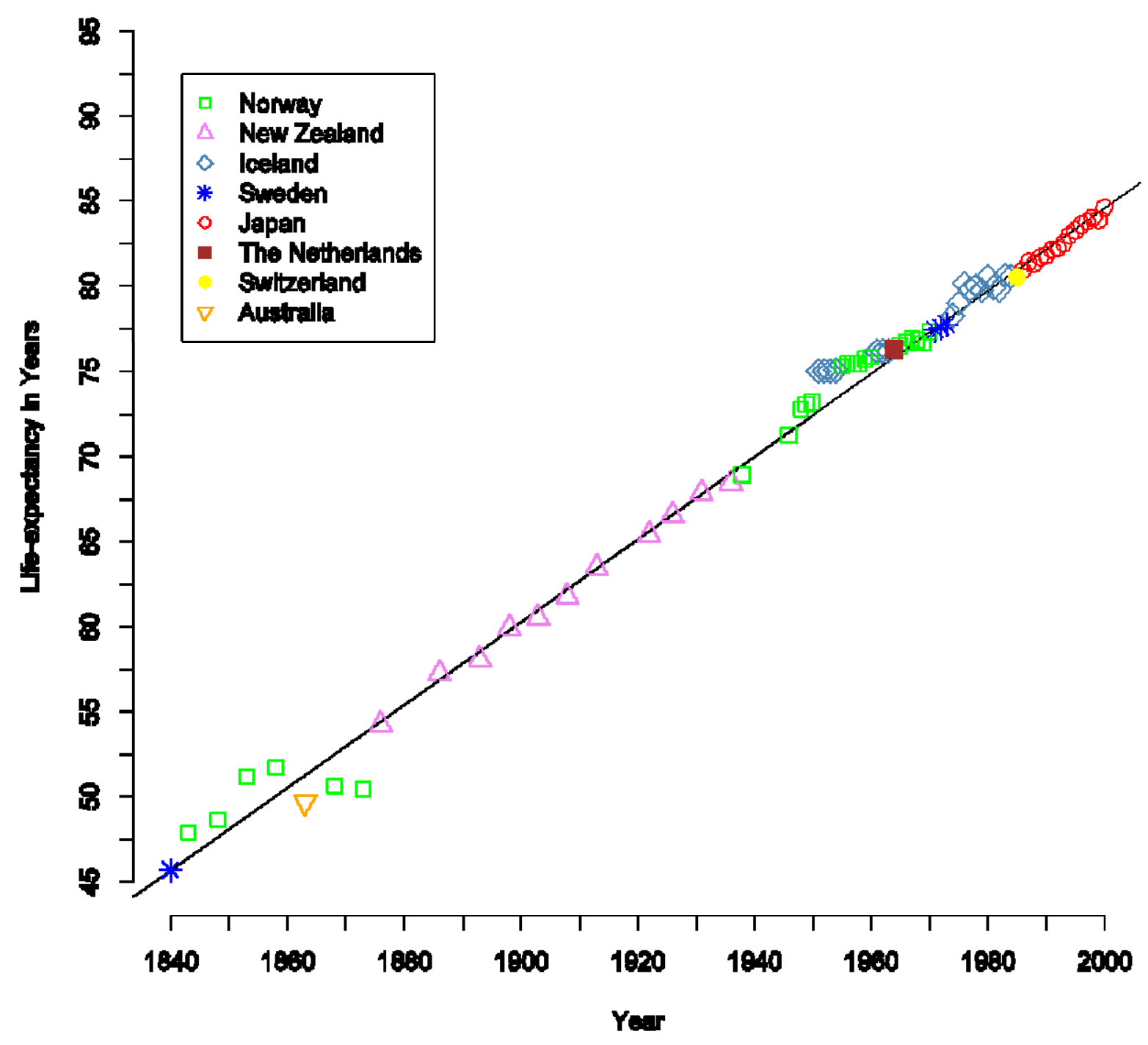

Source: Supplemental Material of Oeppen and Vaupel (2002) 
Figure 1.2: Probability of Dying $q(x)$ for Ages 80, 85, and 90 from 1950 until 2001 for France, Sweden (2002), and Japan

$q(x)$, France, Women

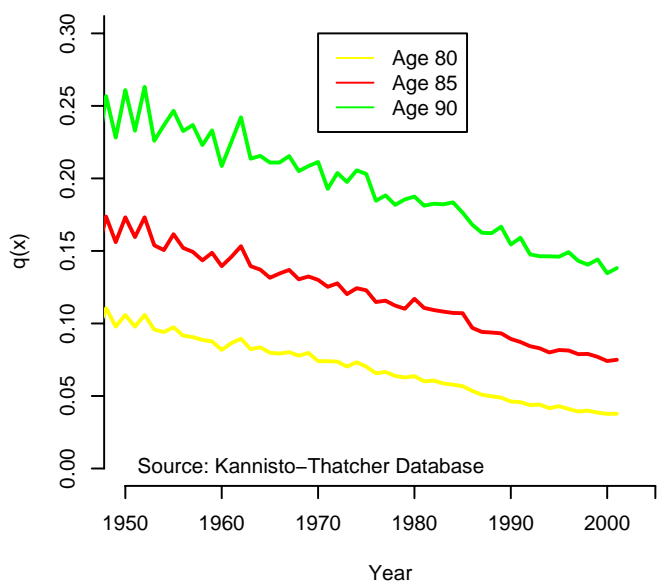

$q(x)$, Sweden, Women

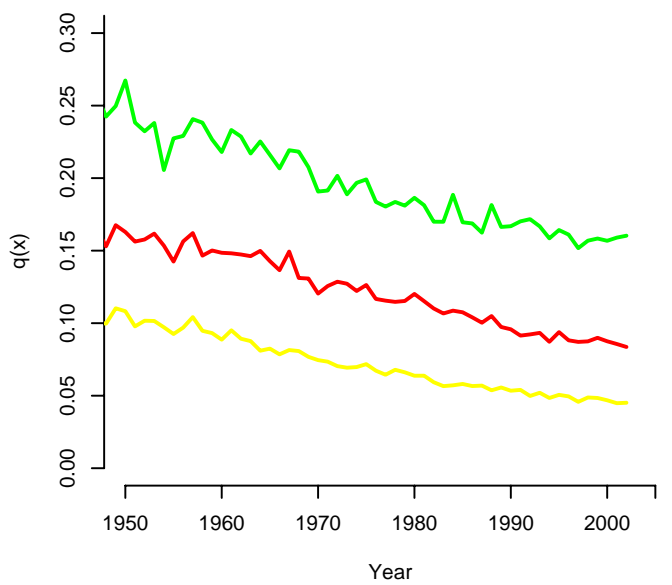

$q(x)$, Japan, Women

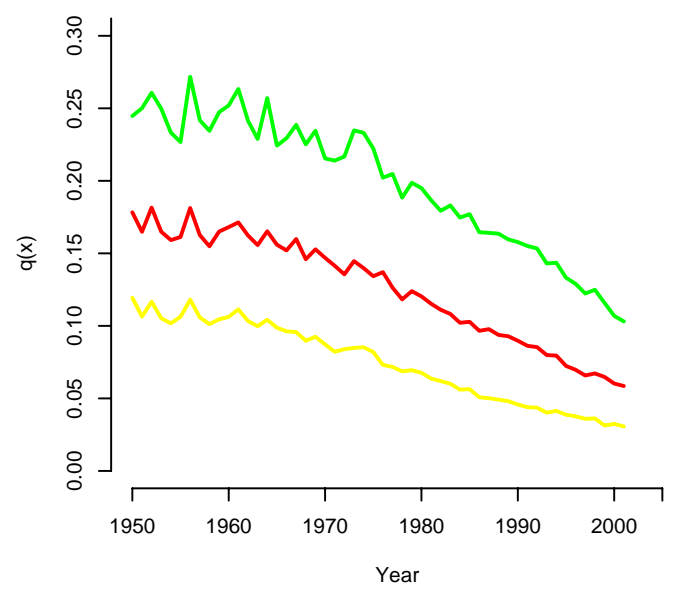

$q(x)$, France, Men

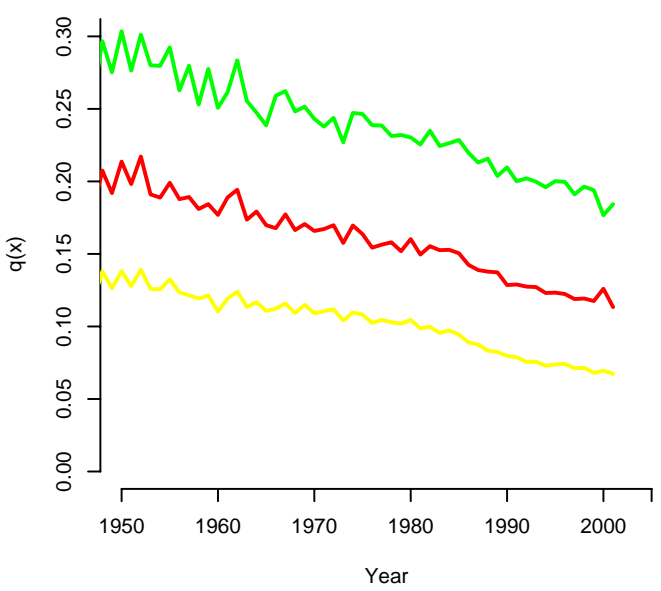

$q(x)$, Sweden, Men

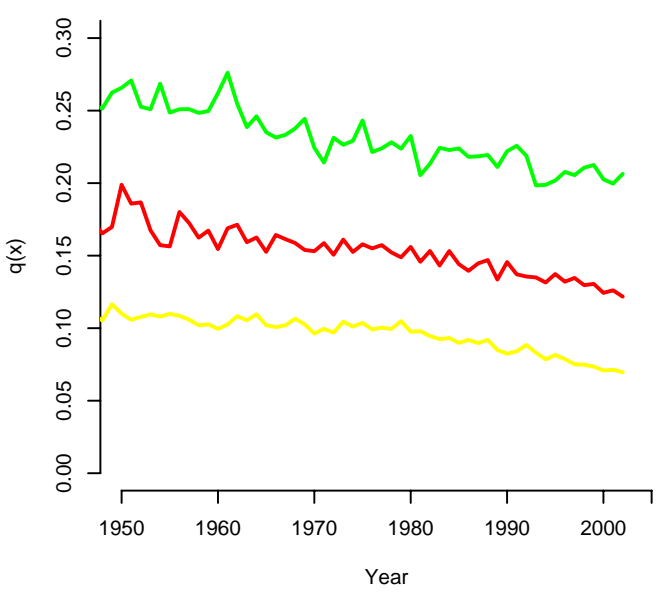

$q(x)$, Japan, Men

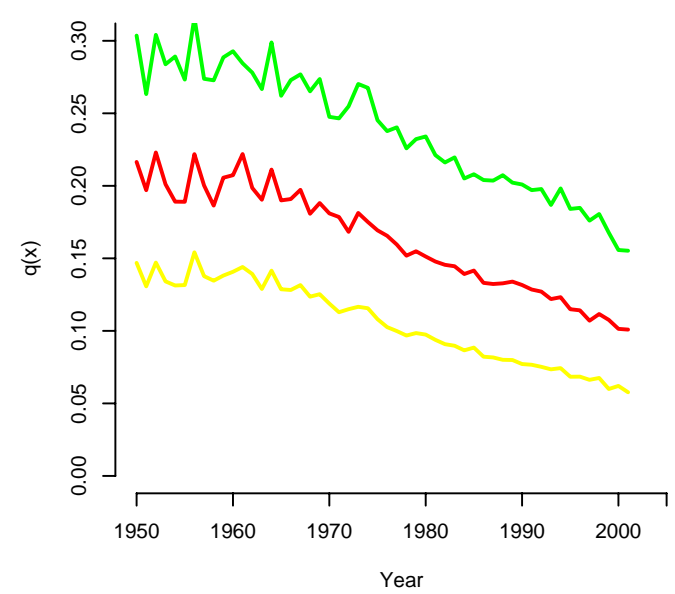

Source: Own estimations based on data from the Kannisto-Thatcher Database 
Table 1.1: Probability of Dying $q(x)$ for Japanese Women at Ages 80, 85, and 90 in 1950 and 2000, Proportion of Mortality in 2000 in Relation to 1950 (Proportion) and Average Annual Improvement in Percent (Improvement).

\begin{tabular}{ccccc}
\hline \hline Age & 1950 & 2000 & Proportion & Improvement \\
\hline 80 & 0.1194 & 0.0324 & 0.2717 & 2.6064 \\
85 & 0.1783 & 0.0602 & 0.3379 & 2.1700 \\
90 & 0.2447 & 0.1069 & 0.4370 & 1.6557 \\
\hline
\end{tabular}

Source: Own estimations based on data from the Kannisto-Thatcher Database 
Figure 1.3: Record Life Expectancy from 1840 to 2000 and Life Expectancy for the United States and other Selected Countries

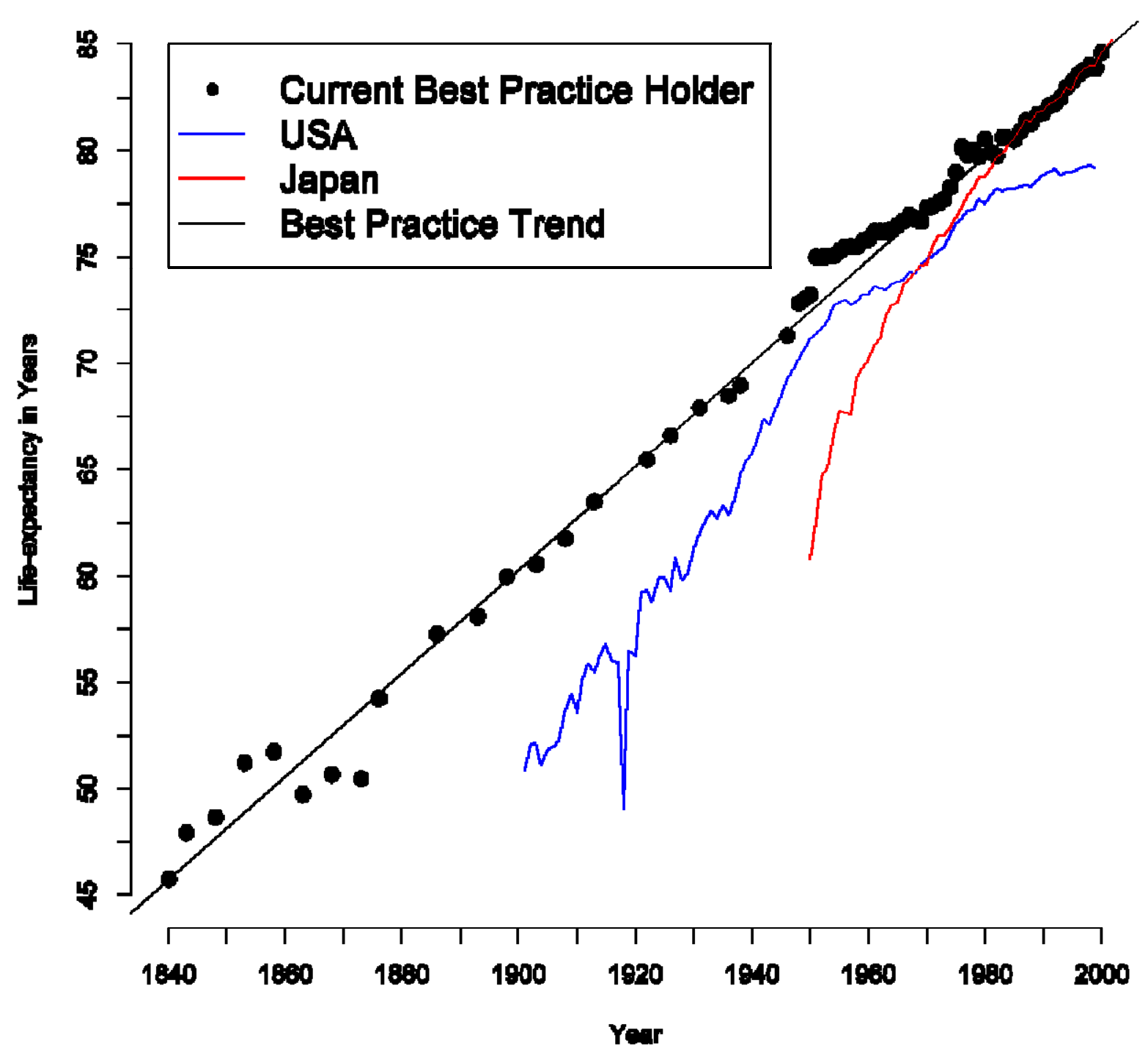

Source: Supplemental Material of Oeppen and Vaupel (2002), Human Lifetable Database (USA), Human Mortality Database (Japan) 
Figure 1.4: Probability of Dying $q(x)$ for Ages 80, 85, and 90 from 1950 until 2001 for the United States (1959-2000), France, Sweden and Japan

$q(x)$, Women, Age 80

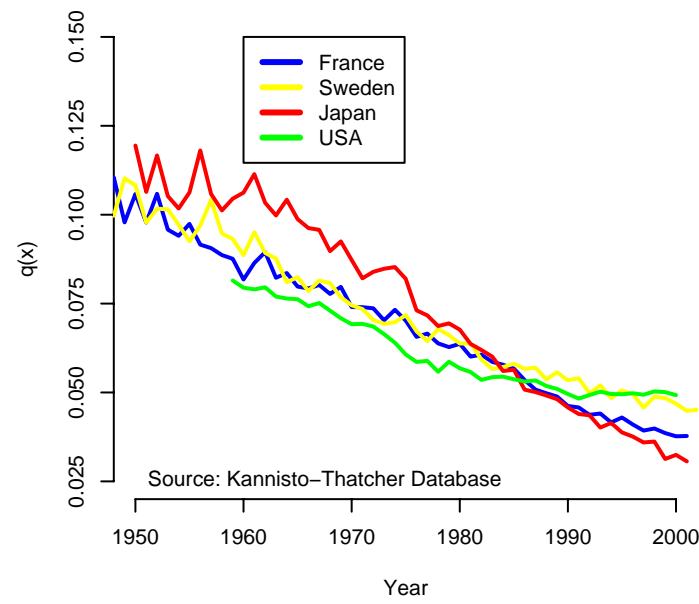

$q(x)$, Women, Age 85

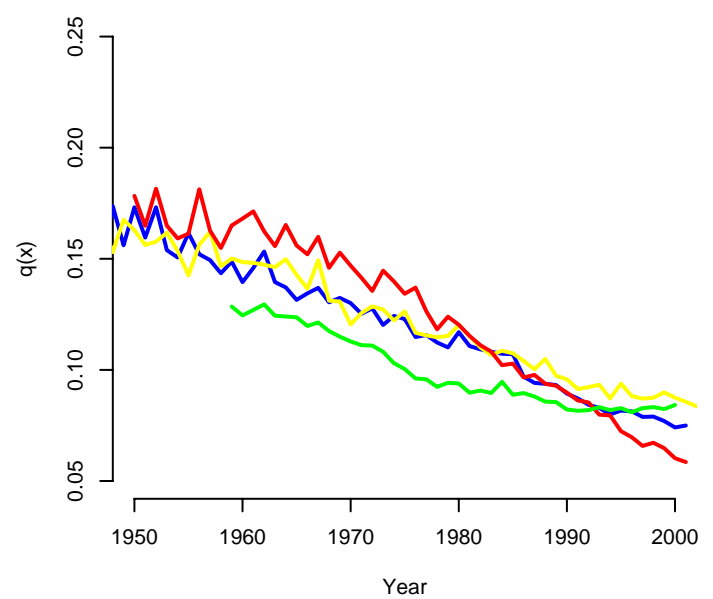

$q(x)$, Women, Age 90

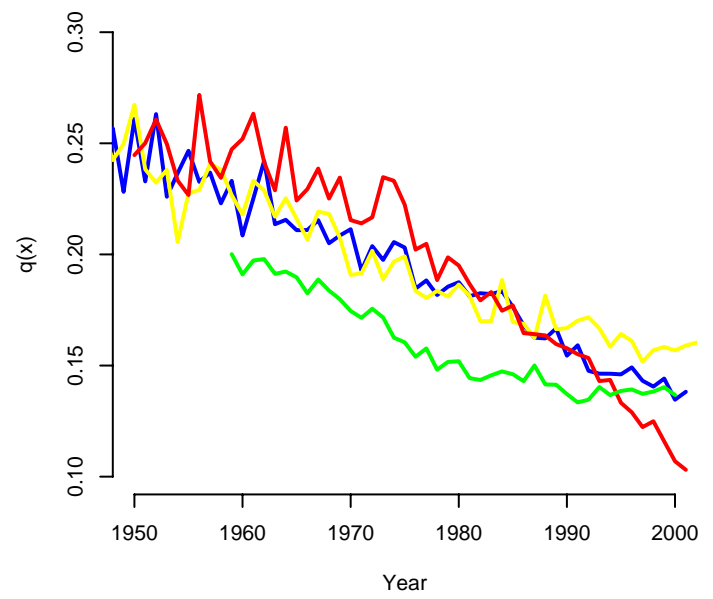

$q(x)$, Men, Age 80

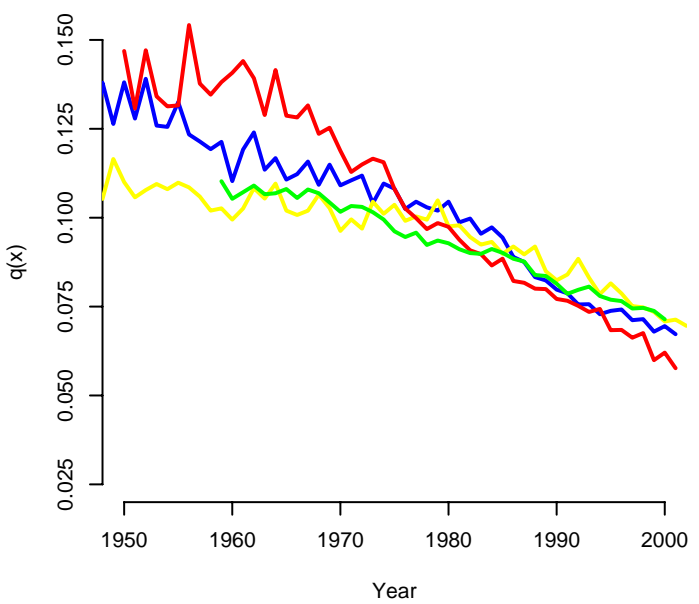

$q(x)$, Men, Age 85

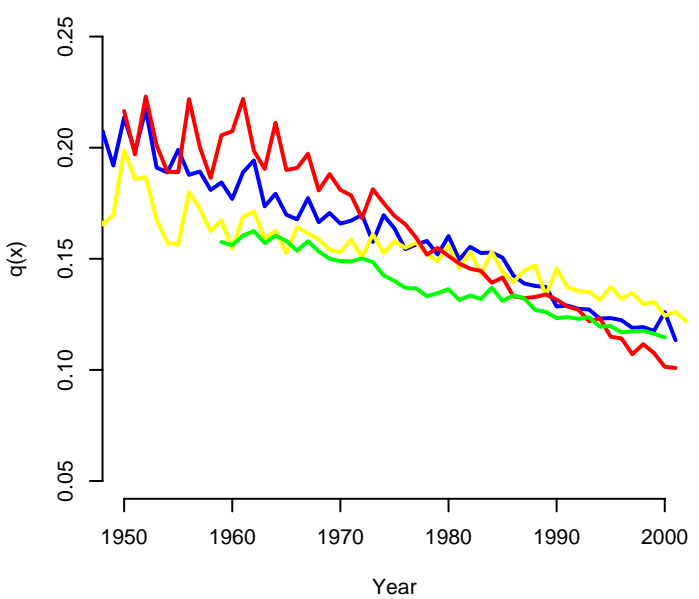

$q(x)$, Men, Age 90

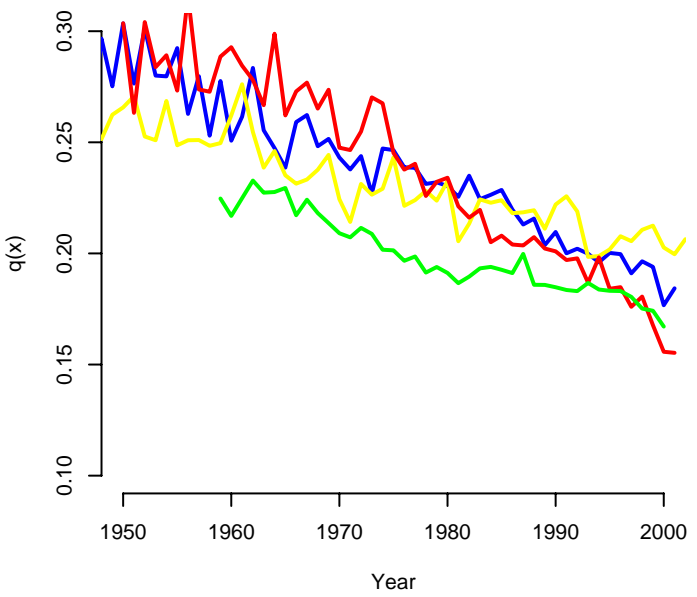


Source: Own estimations based on data from the Kannisto-Thatcher Database 
Figure 1.5: Average Annual Improvement in Female Mortality for Age-Groups 80-84, 85-89, 90-94 in Japan and the United States

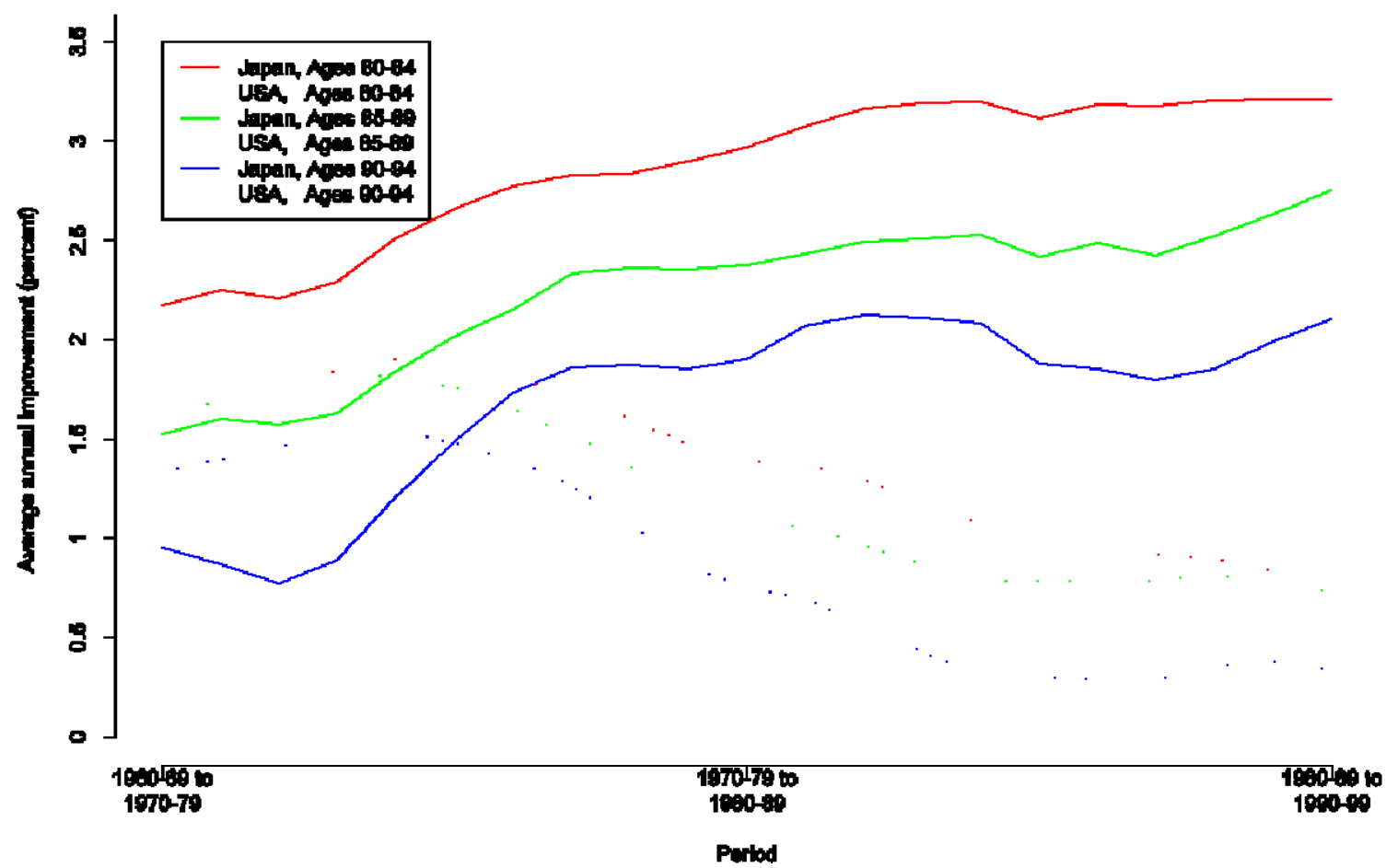

Source: Own estimation based on data from the Kannisto-Thatcher-Database. The curves plot the annual average improvement in mortality between successive ten-year-periods. The first point gives the rate of improvement between 1970-79 and 1960-69 for the three 5-year-age-groups. 
Figure 2.1: Official Estimates of Mortality at Ages 65 to 100 by State in the United States for the Years 1989/1991

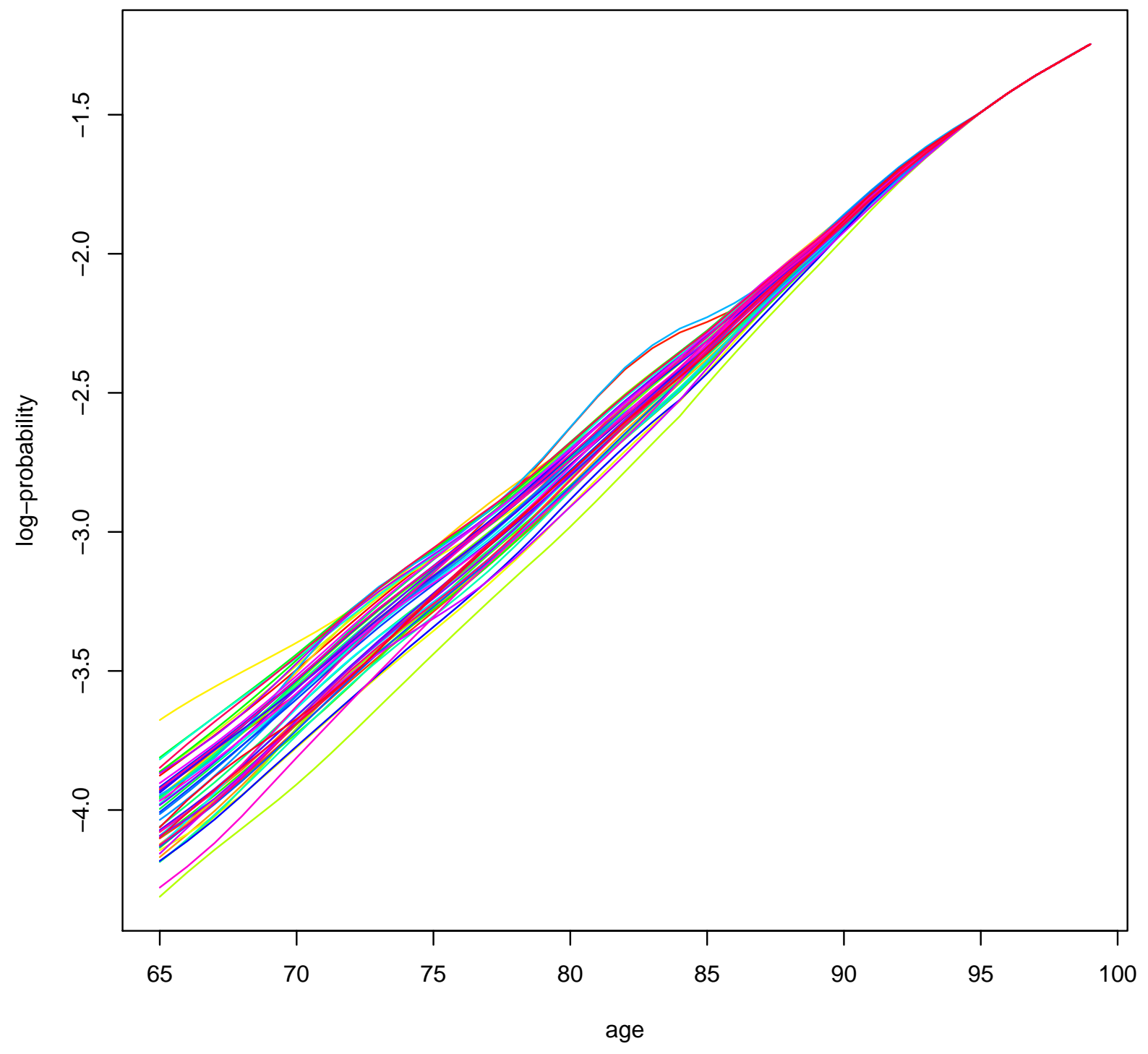

Source: Own estimations based on NCHS Data 
Table 2.1: Size of Analyzed Data-Set

\begin{tabular}{clr}
\hline \hline Code & Meaning & Counts \\
\hline 0 & Unkown & 2 \\
1 & Male & $8,422,716$ \\
2 & Female & $11,536,799$ \\
\hline- & $\sum$ & $19,959,517$ \\
\hline \hline
\end{tabular}

Source: Own estimations based on data from the Social Security Administration 
Table 3.1: Top-5 Performing States for Each Indicator Listed Alphabetically Excluding District of Columbia

\begin{tabular}{ccc}
\multicolumn{3}{c}{ Indicator } \\
\hline Life Expectancy & Median Income & Gross State Product \\
(White Women, 1990) & $(1985)$ & $(1985)$ \\
\hline Hawaii & Alaska & Alaska \\
Iowa & Connecticut & Connecticut \\
Minnesota & Maryland & Delaware \\
North Dakota & Massachusetts & New York \\
South Dakota & New Jersey & Wyoming \\
\hline \hline
\end{tabular}


Figure 3.1: Probability of Dying for Japanese Women Aged 80-100 Years between 1976 and 1994

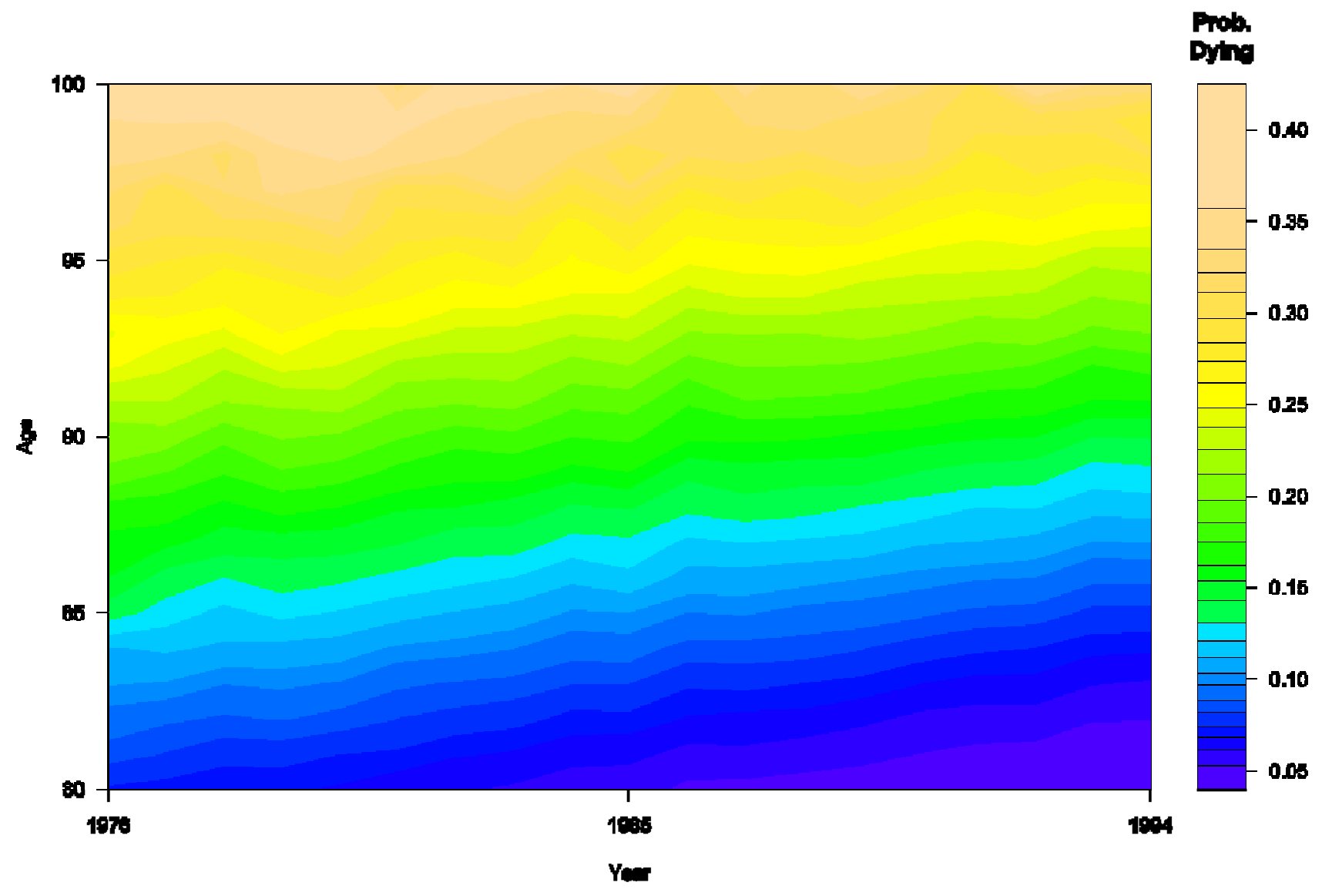

Source: Own estimations based on data from the Kannisto-Thatcher-Database 
Figure 3.2: Probability of Dying for White Women Aged 80-100 Years between 1976 and 1994 in the Five States of the United States Performing Best in Terms of Life Expectancy Among White Women in 1990 (Hawaii, Iowa, Minnesota, North Dakota, South Dakota)

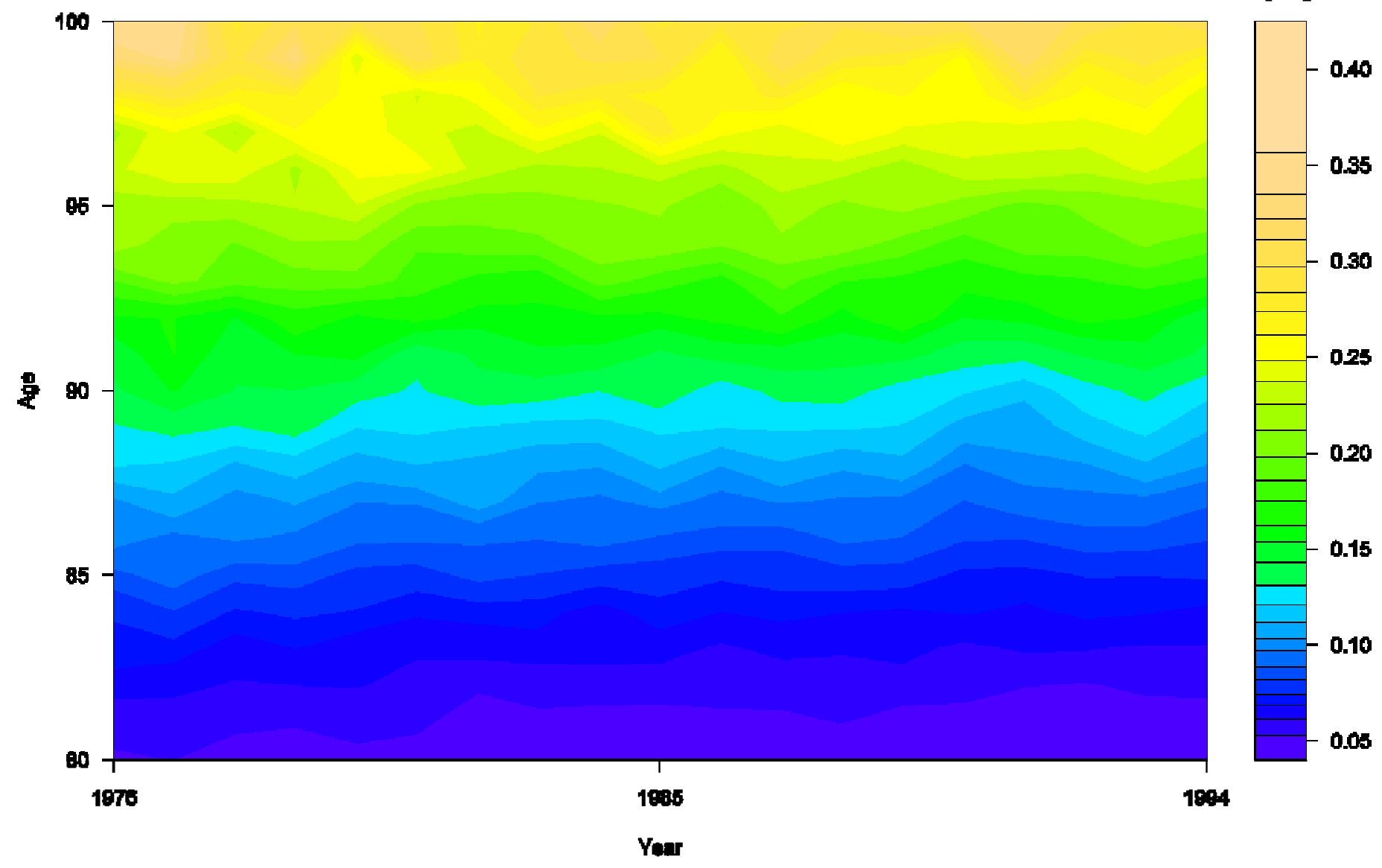

Source: Own estimations based on data from the Kannisto-Thatcher-Database 
Figure 3.3: Probability of Dying between 1976 and 1994 for 80- and 85-year-old Japanese Women (blue), US-Women (green) and White Women (red) in the Five States of the United States Performing Best in Terms of Life Expectancy Among White Women in 1990 (Hawaii, Iowa, Minnesota, North Dakota, South Dakota)
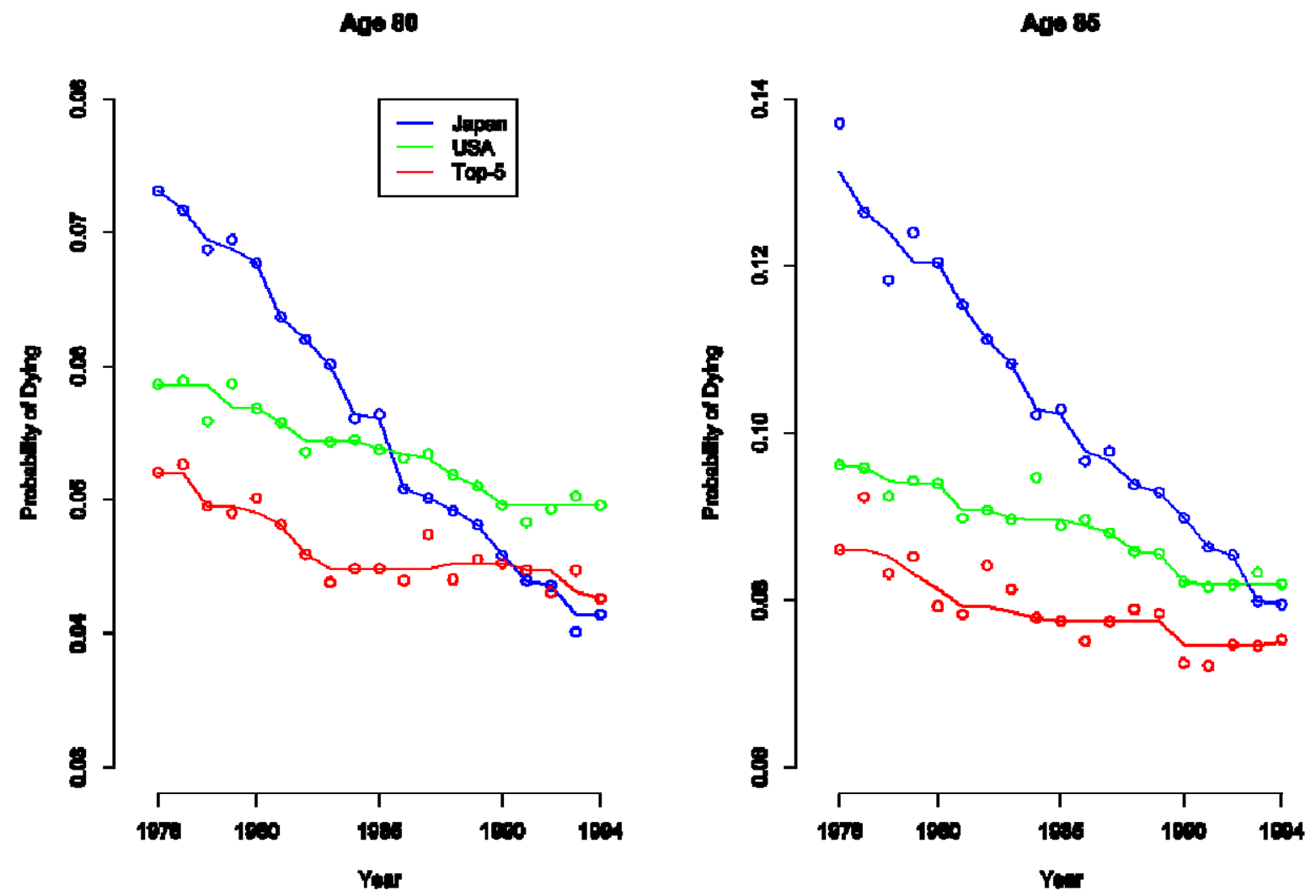

Source: Own estimations based on data from the Kannisto-Thatcher-Database and from the Social Security Administration 
Figure 3.4: Probability of Dying for White Women Aged 80-100 Years between 1976 and 1994 in the Five States of the United States Performing Best in Terms of Median Household Income in 1985 (Alaska, Connecticut, Maryland, Massachusetts, New Jersey)

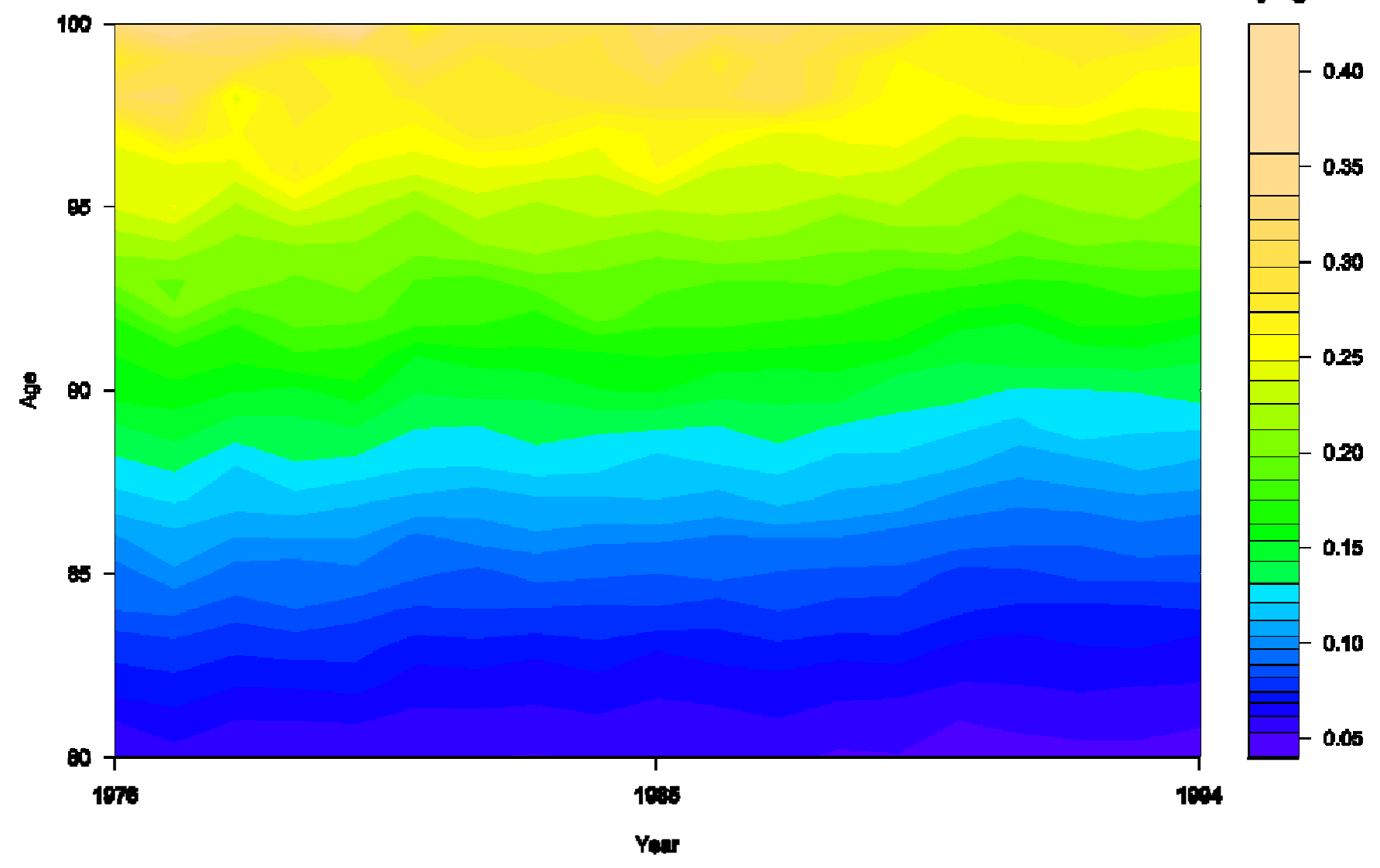

Source: Own estimations based on data from the Kannisto-Thatcher-Database 
Figure 3.5: Probability of Dying between 1976 and 1994 for 80- and 85-year-old Japanese Women (blue), US-Women (green) and White Women (red) in the Five States of the United States Performing Best in Terms of Median Household Income in 1985 (Alaska, Connecticut, Maryland, Massachusetts, New Jersey)

Age 60

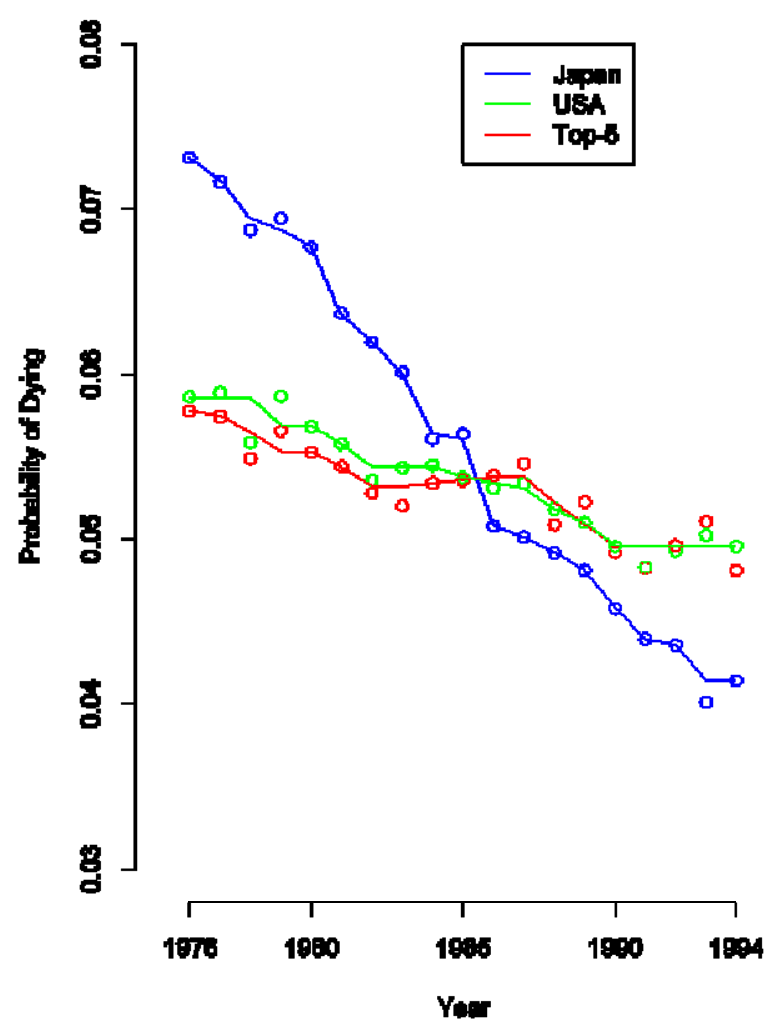

Ape 86

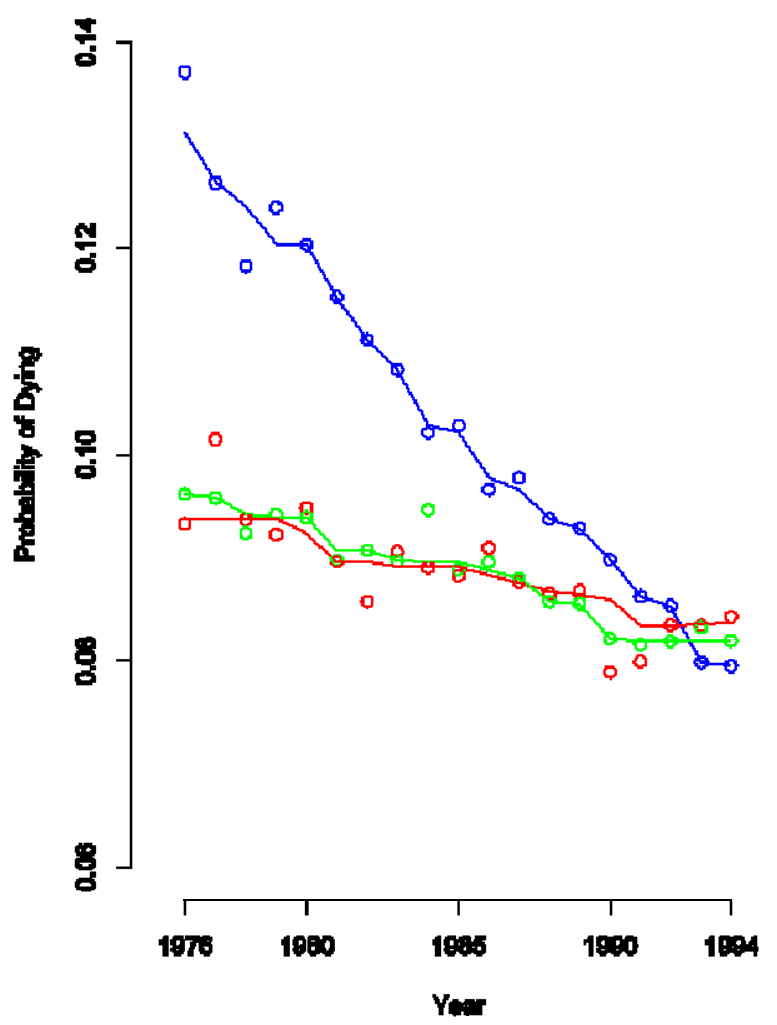

Source: Own estimations based on data from the Kannisto-Thatcher-Database and from the Social Security Administration 
Figure 3.6: Probability of Dying for White Women Aged 80-100 Years between 1976 and 1994 in the Five States of the United States Performing Best in Terms of GDP per Head in 1985 (Alaska, Connecticut, Delaware, New York, Wyoming)

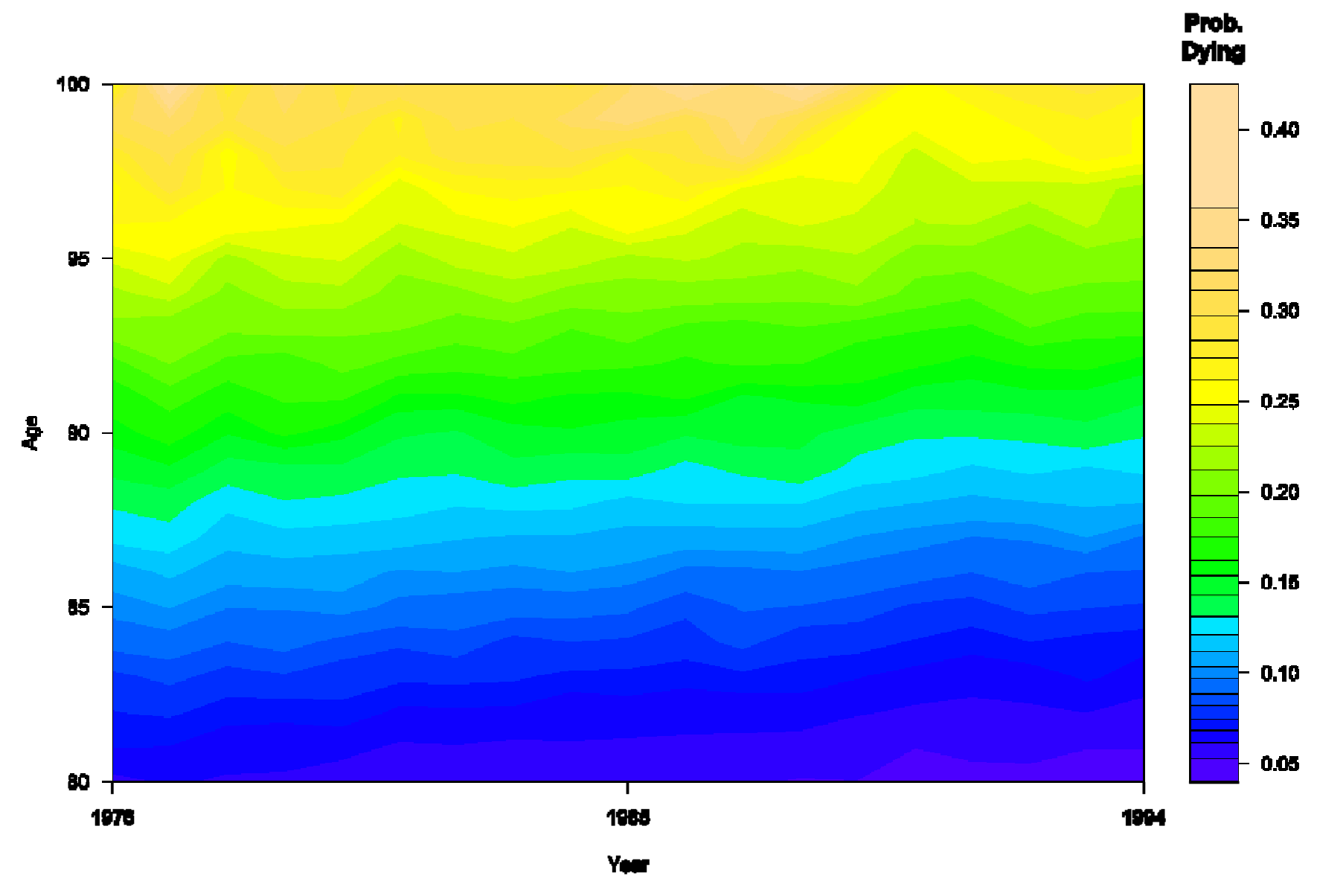

Source: Own estimations based on data from the Kannisto-Thatcher-Database 
Figure 3.7: Probability of Dying between 1976 and 1994 for 80- and 85-year-old Japanese Women (blue), US-Women (green) and White Women (red) in the Five States of the United States Performing Best in Terms of GDP per Head in 1985 (Alaska, Connecticut, Delaware, New York, Wyoming)

Age 80

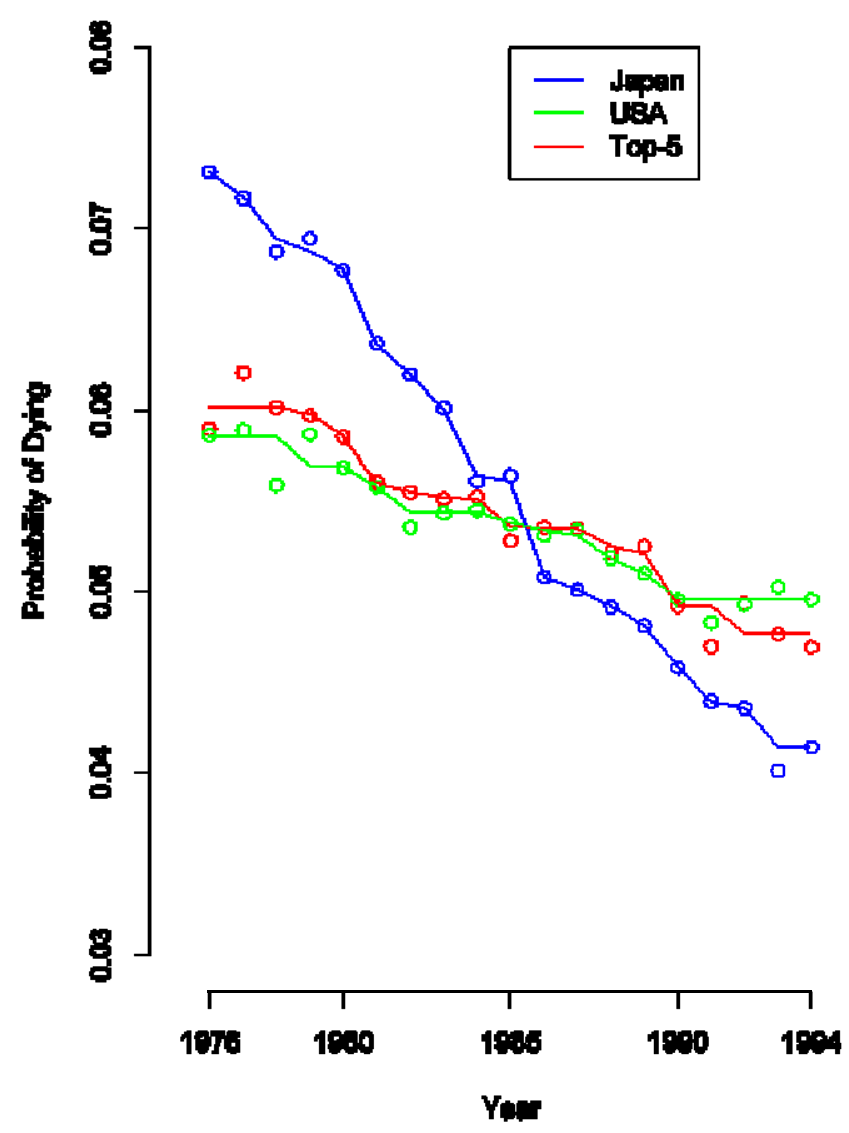

Age 86

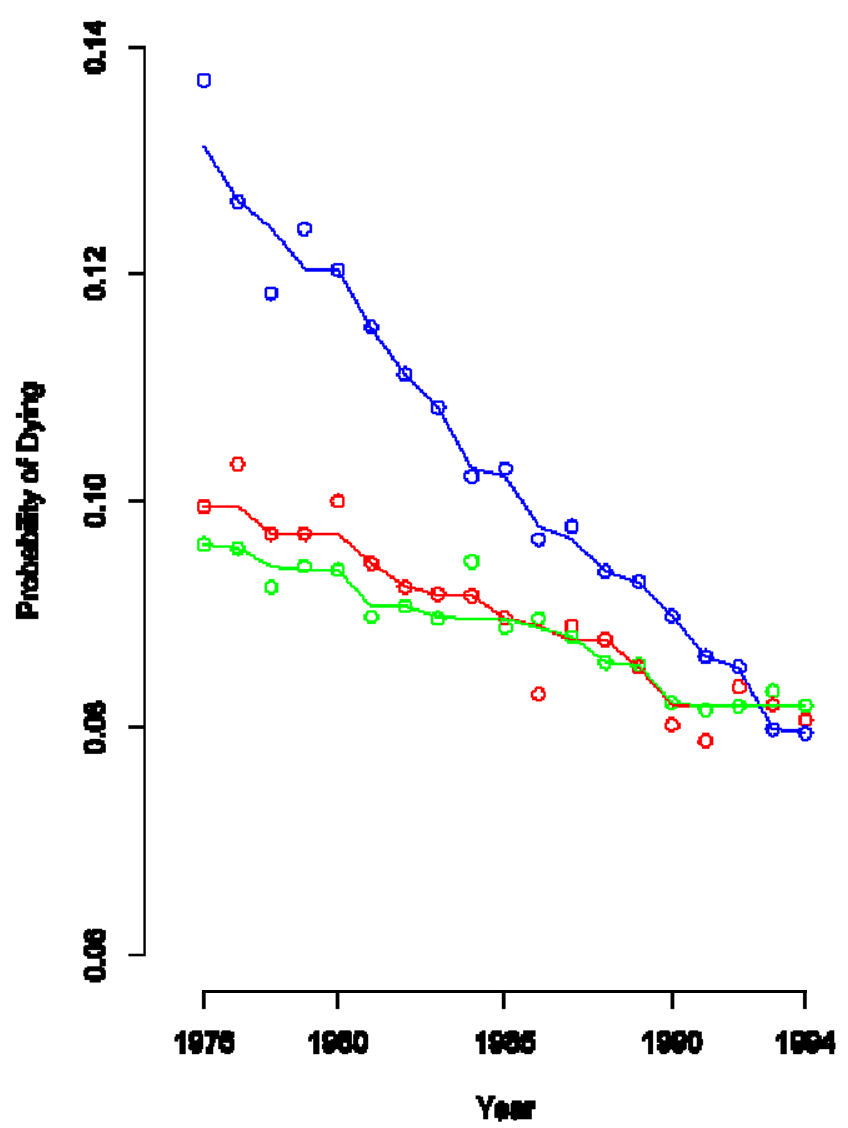

Source: Own estimations eased on data from the Kannisto-Thatcher-Database and from the Social Security Administration 


\section{Appendix: Data Quality}

Figure A1: Mortality Rates in the United States by Calendar Year and Age on a Lexis Surface, Women and Men Combined, 1966-1996, Ages 65-99

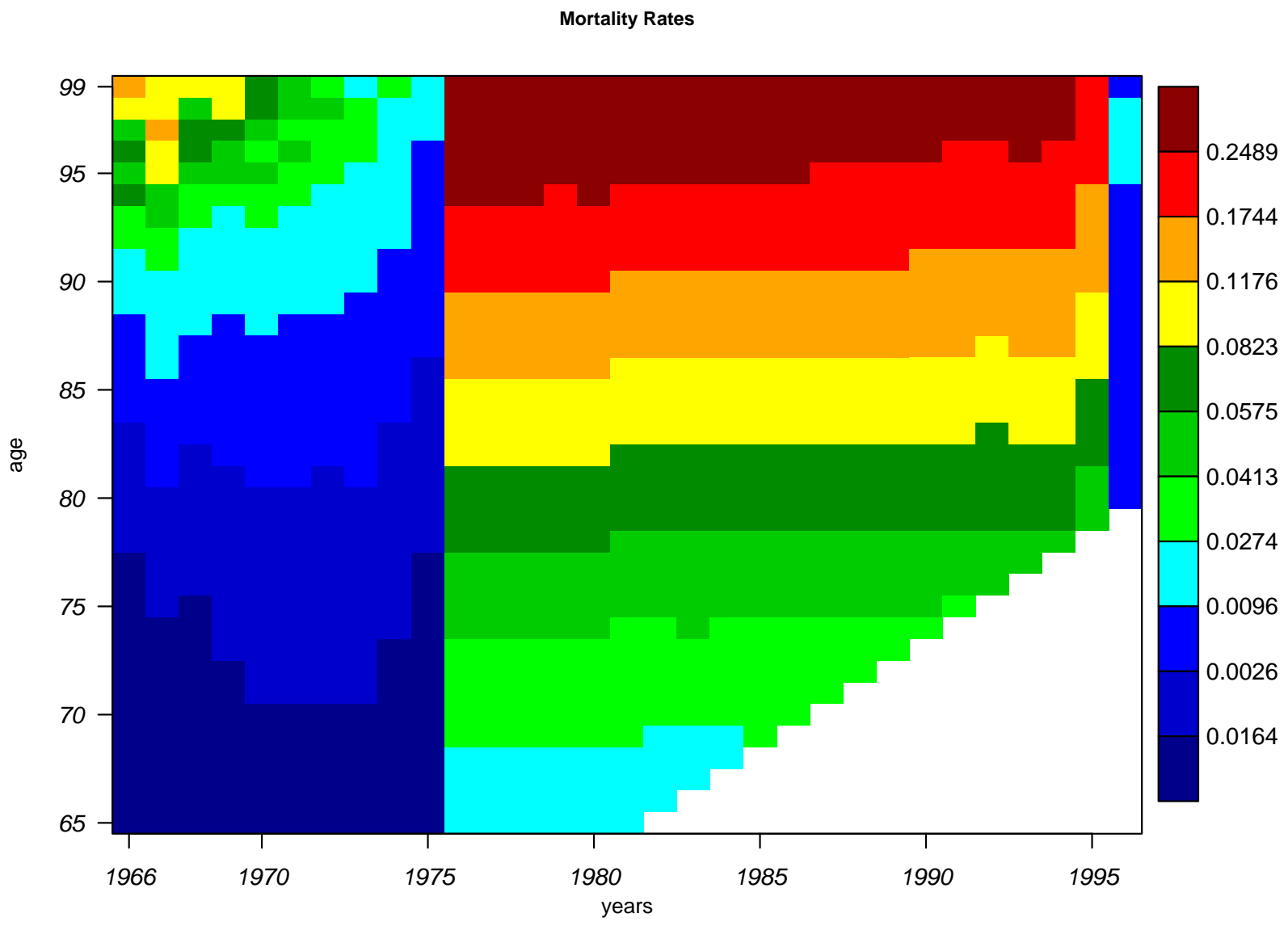

Source: Own estimations based on Social Security data 
Figure A2: Comparing our Estimates for the Probability of Dying of Women and Men combined, 1976-94, Ages 65-99 with Results from the Human Mortality Database (HMD)

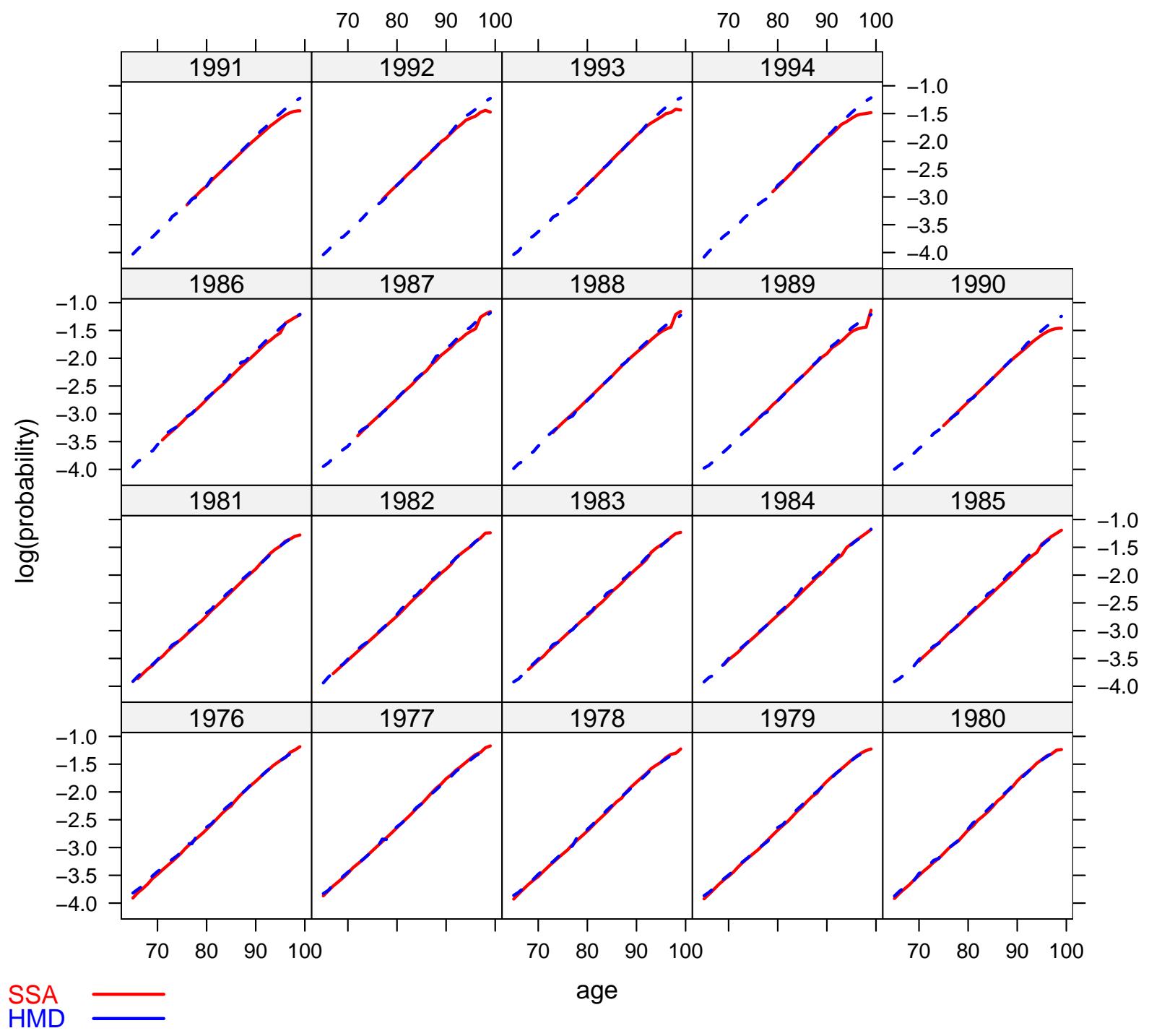

Source: Own estimations based on Social Security data, HMD 
Figure A3: Comparing our Estimates for the Probability of Dying of Women, 1976-94, Ages 6599 with Results from the Human Mortality Database (HMD)

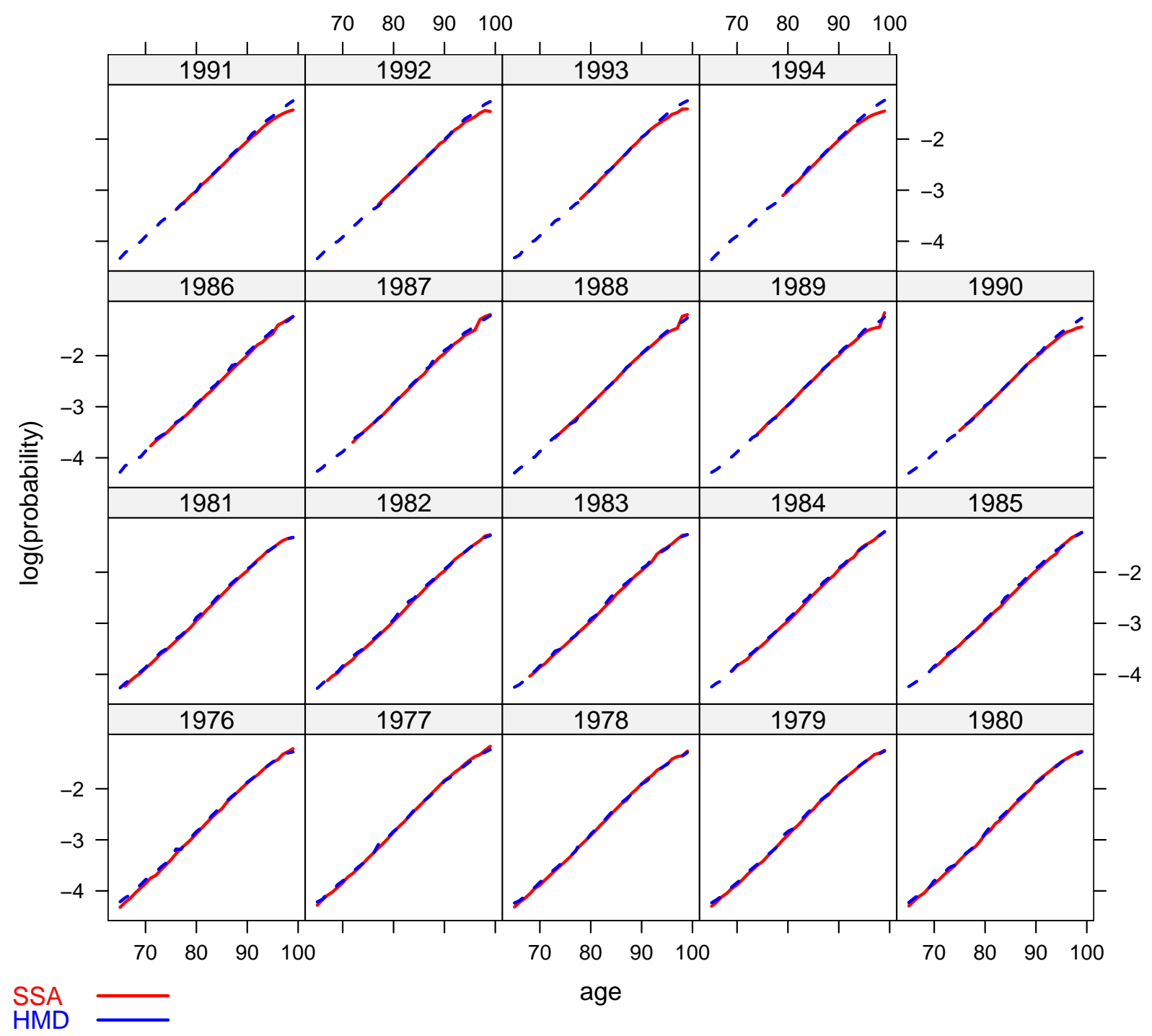

Source: Own estimations based on Social Security data, HMD 
Figure A4: Comparing our Estimates for the Probability of Dying of Men, 1976-94, Ages 65-99 with Results from the Human Mortality Database (HMD)

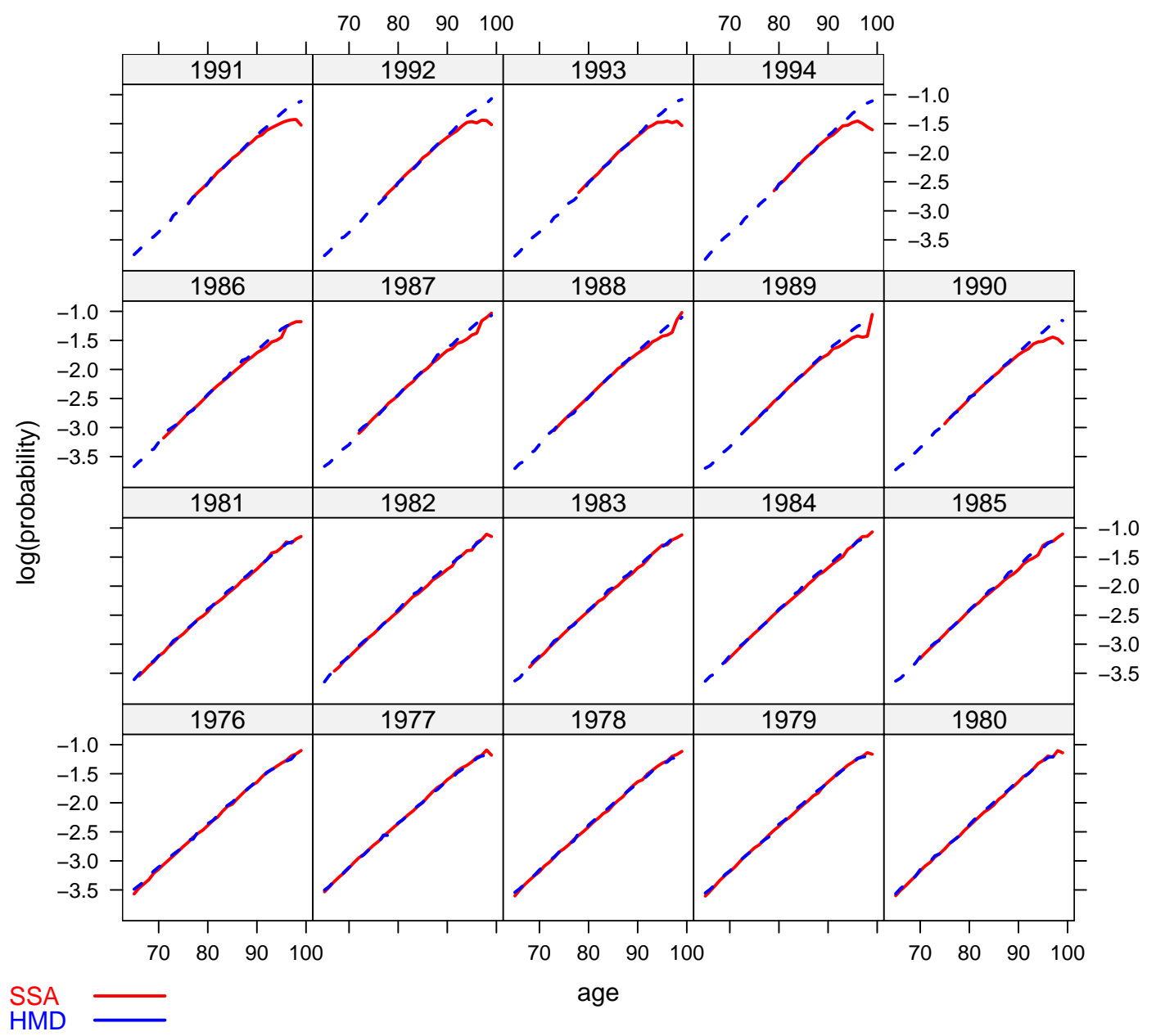

Source: Own estimations based on Social Security data, HMD 


\section{Method}

It is impossible to estimate mortality for one year of age, during one year of calendar time for a one-year-birth-cohort as is shown in Figures A5-A7. Our approach follows Figure A5 where the number of deaths is indicated by the green parallelogram. The population at risk is indicated by the red line between " $\mathrm{A}$ " and "B". That implies that we calculate mortality for an exact birth-cohort for the exact age. Calendar Time is, however, spread over two calendar years. The means that mortality for year $y$ is measured for the 1 st of January of year $y$.

Figure A5: Exact Age and Exact Birth Year, Overlapping Death Years

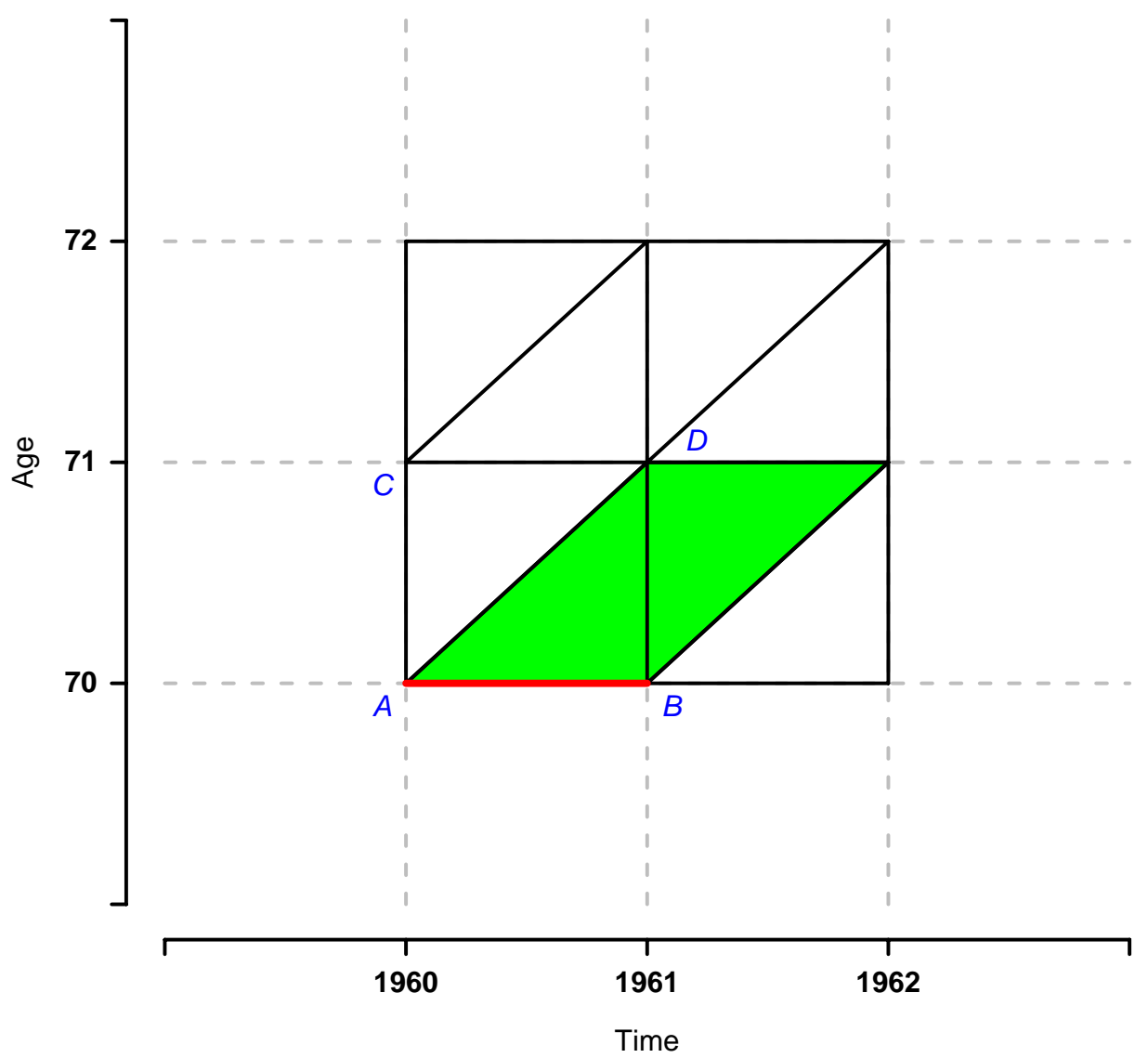


Figure A6: Exact Age and Exact Death Year, Overlapping Birth Years

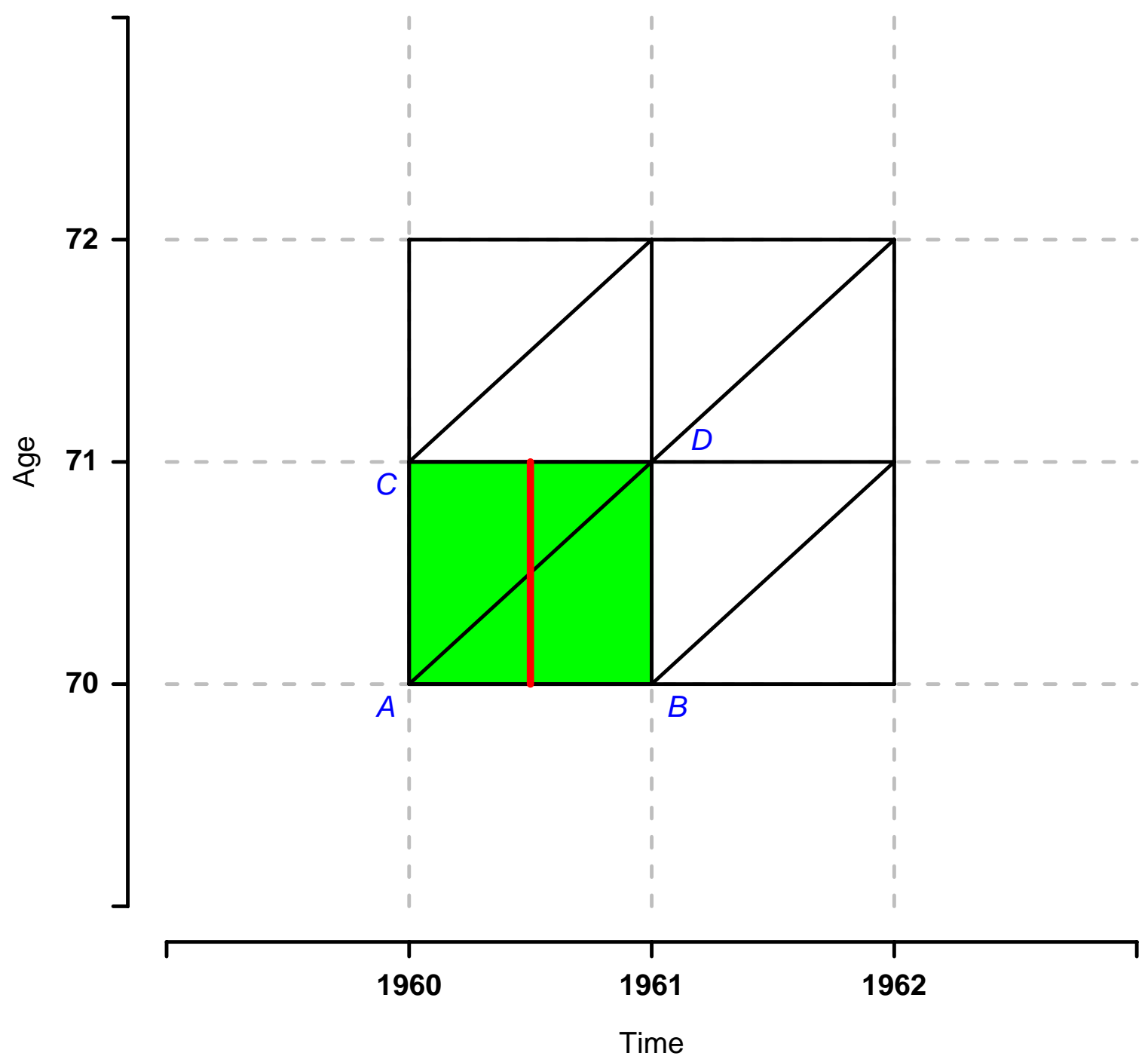


Figure A7: Exact Birth Year and Exact Death Year, Overlapping Ages

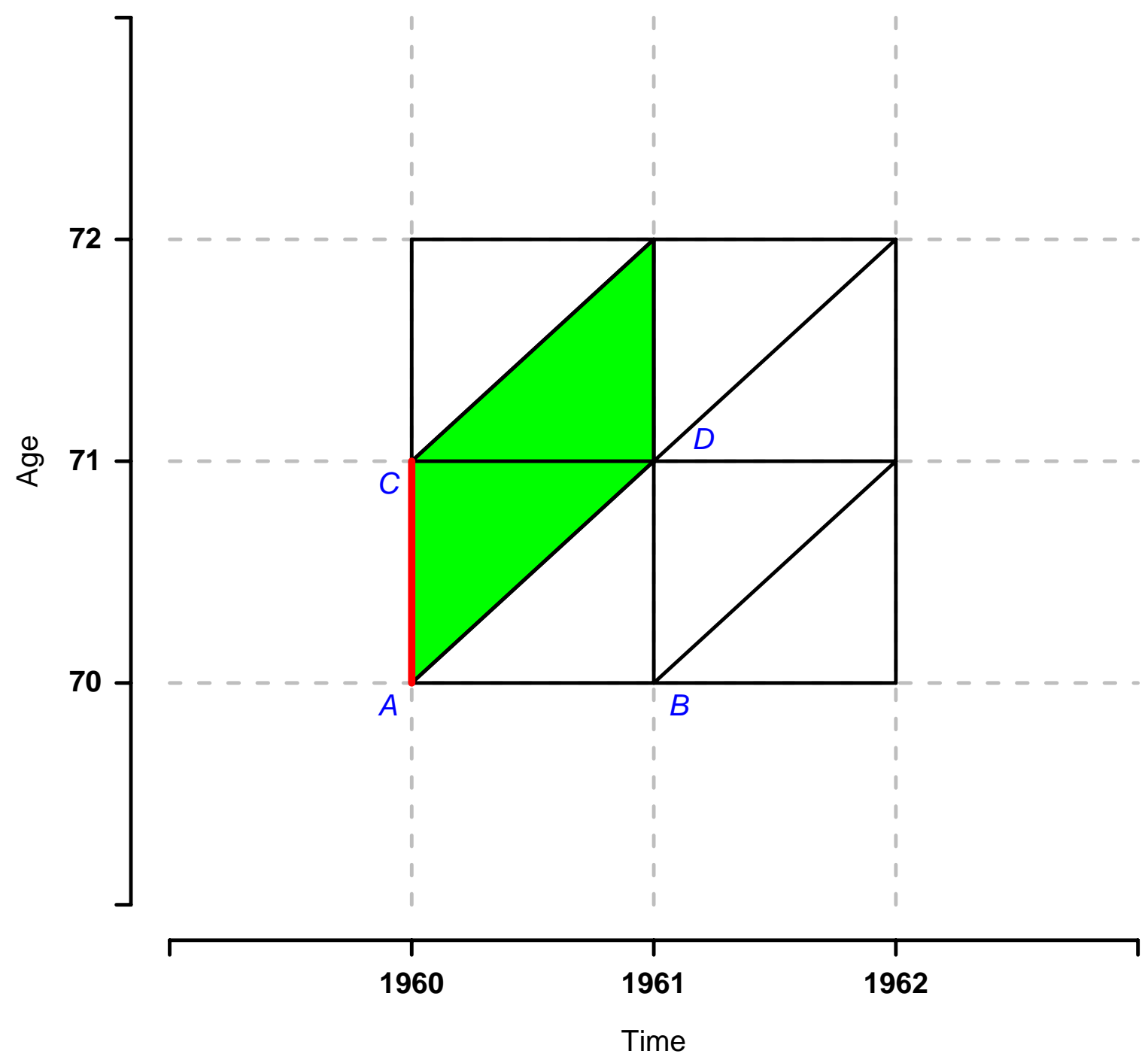




\section{RECENT WORKING PAPERS FROM THE \\ CENTER FOR RETIREMENT RESEARCH AT BOSTON COLLEGE}

Personalized Retirement Advice and Managed Accounts: Who Uses Them and How Does Advice Affect Behavior in 401(k) Plans?

Julie Agnew, March 2006

Working for a Good Retirement

Barbara A. Butrica, Karen E. Smith and C. Eugene Steuerle, March 2006

The Politics of Parallel Pensions: Lessons from the United Kingdom for the United States

R. Kent Weaver, February 2006

Cross-National Evidence on the Fiscal Burden of Public and Private Finance of Old-Age Consumption

Gary Burtless, February 2006

The Effects of Population Aging on Labor Demand

Bob Triest, Steven Sass and Margarita Sapozhnikov, February 2006

Financing Disability Benefits in a System of Individual Accounts: Lessons from International Experience

Patrick Wiese, February 2006

Long-Term Immigration Projection Methods: Current Practice and How to Improve it

Neil Howe and Richard Jackson, February 2006

Policies to Promote Labor Force Participation of Older Workers

Alicia H. Munnell, January 2006

Demographic Private Transfers in a Cross Section of Developing Countries

Donald Cox, Emanuela Galasso and Emmanuel Jiminez, January 2006

Making Maximum Use of Tax-Deferred Retirement Accounts

Janette Kawachi, Karen Smith and Eric Toder, January 2006

When the Nest Egg Cracks: Financial Consequences of Health Problems, Marital Status Changes, and Job Layoffs at Older Ages.

Richard W. Johnson, Gordon B.T. Mermin and Cori E. Uccello, December 2005

All working papers are available on the Center for Retirement Research website

(http://www.bc.edu/crr) and can be requested by e-mail (crr@bc.edu) or phone (617-552-1762). 